\title{
Use of a Coupled Land Surface General Circulation Model to Examine the Impacts of Doubled Stomatal Resistance on the Water Resources of the American Southwest
}

\author{
Marian Martin, Robert E. Dickinson, AND Zong-Liang Yang \\ Institute of Atmospheric Physics, The University of Arizona, Tucson, Arizona
}

(Manuscript received 6 July 1998, in final form 25 January 1999)

\begin{abstract}
Tiny openings on the surfaces of leaves, stomata, control the flux of $\mathrm{CO}_{2}$, water vapor, and other gases between the atmosphere and the earth's vegetated surface. An increase in atmospheric $\mathrm{CO}_{2}$ could have an effect on stomatal openings, causing indirect changes in many surface hydroclimatogical variables that could be comparable in magnitude to the direct radiative effects. Increased atmospheric $\mathrm{CO}_{2}$ is expected to increase water use efficiency in many plant types because of the closure of the stomatal openings on the leaf surface. The present study assesses this stomatal effect by doubling the stomatal resistance in two land surface schemes, the BiosphereAtmosphere Transfer Scheme and the Land Surface Model, which are coupled to the National Center for Atmospheric Research's Community Climate Model version 3 atmospheric general circulation model, and by evaluating the resulting hydrometeorological responses, particularly for the western United States.

Because the simulated reduction of stomatal openings restricts evapotranspiration, latent heat fluxes are reduced, causing global average annual and seasonal decreases in precipitation as well as increases in sensible heat flux, surface temperatures, runoff, and root-zone soil water. Global seasonal decreases in latent heat flux of up to $7 \%$ occur, corresponding to surface temperature increases of up to $0.5^{\circ} \mathrm{C}$ and precipitation decreases of up to $3 \%$. Regional responses vary.

A focus of this study was to examine how these changes affect runoff and stream flow in the southwestern United States. Contrary to a previous empirical study of this effect, which showed an $87 \%$ mean increase in Arizona basin stream flow, this coupled land surface-atmospheric model shows no significant changes in any of the variables examined for this region.
\end{abstract}

\section{Introduction}

\section{a. Dependence of transpiration on $\mathrm{CO}_{2}$}

A number of studies have indicated that plants may respond to an increased $\mathrm{CO}_{2}$ environment by reducing their transpiration rates (e.g., Morison and Gifford 1984; Eamus and Jarvis 1989; Bazzaz and Fajer 1992; Radoglou et al. 1992). Plants accomplish this by partially closing their stomata, the small openings on the leaf surface that allow for the fluxes of $\mathrm{CO}_{2}$, water vapor, and other gases between the leaf and its environment. Because the stomata act to maximize $\mathrm{CO}_{2}$ intake while minimizing water loss, surplus $\mathrm{CO}_{2}$ in the environment may allow the plant to increase its water use efficiency by increasing carbon fixation while maintaining or reducing transpiration rates on a per unit leaf area basis. Assuming that the vegetation does not respond to the increase in $\mathrm{CO}_{2}$ by growing larger leaf areas, the net result would be an overall reduction in transpiration rates. Since vegetation covers much of the land surface,

Corresponding author address: Marian Martin, 11512 Mapleview Drive, Silver Spring, MD 20902.

E-mail: mmartin@icfconsulting.com these changes have the potential to affect climate when applied on a global scale. Stomatal responses vary greatly by plant type (Eamus and Jarvis 1989; Hileman et al. 1992), and are not understood in enough detail to be explicitly included in climate models. Some land surface models, such as the improved simple biosphere model (SiB2) (Sellers et al. 1992), incorporate a plant physiology that will respond to increased $\mathrm{CO}_{2}$ concentrations and increase stomatal resistance, but they assume a universal functional relationship between stomatal resistance and $\mathrm{CO}_{2}$ concentration for all plants at all locations. No further level of detail has been incorporated into general circulation models (GCMs).

Our research focuses on the possible effect of stomatal response on the water resources of the waterstrapped American southwest by incorporating an increased stomatal resistance into a coupled land-atmosphere GCM. Greenhouse experiments have shown that in a doubled $\mathrm{CO}_{2}$ environment, plants increase their stomatal resistance by a factor of 1.5 to 2 (Morison and Gifford 1984); thus, this and other studies have used a doubled stomatal resistance to analyze how increased $\mathrm{CO}_{2}$ might affect global climate through its effect on transpiration (e.g., Henderson-Sellers et al. 1995; Pollard and Thompson 1995). In addition, this study com- 
TABLE 1. Sensitivity of water supply variables to changes in natural flow in the Colorado River basin (from Nash 1991). Numbers in parentheses represent decreases.

\begin{tabular}{|c|c|c|c|c|c|}
\hline $\begin{array}{c}\text { Change in } \\
\text { natural flow } \\
(\%)\end{array}$ & $\begin{array}{c}\text { Change in } \\
\text { actual flow } \\
(\%)\end{array}$ & $\begin{array}{c}\text { Change in } \\
\text { storage } \\
(\%)\end{array}$ & $\begin{array}{c}\text { Change in power } \\
\text { generation } \\
(\%)\end{array}$ & $\begin{array}{c}\text { Change in } \\
\text { consumptive } \\
\text { use } \\
(\%)\end{array}$ & $\begin{array}{l}\text { Change in } \\
\text { salinity } \\
(\%)\end{array}$ \\
\hline-20 & $(20-30)$ & (61) & $(57)$ & (11) & $15-20$ \\
\hline-10 & $(7-15)$ & (30) & (31) & (6) & $6-7$ \\
\hline-5 & $(4-7)$ & (14) & (15) & (3) & 3 \\
\hline 5 & $5-7$ & 14 & 11 & 3 & (3) \\
\hline 10 & $11-16$ & 28 & 21 & 5 & $(6-7)$ \\
\hline 20 & 30 & 38 & 39 & 8 & $(13-15)$ \\
\hline
\end{tabular}

pares the impacts of the increased stomatal resistance from two different land surface parameterizations as coupled to the same GCM. It should be noted that this is a sensitivity study of the effects of increased stomatal resistance; therefore, leaf area index and atmospheric $\mathrm{CO}_{2}$ concentrations are held constant.

\section{b. Previous studies of increased stomatal resistance on water resources of the Southwest}

Two studies in particular have examined the impacts of $\mathrm{CO}_{2}$-induced climate change on the water resources of the southwest United States. Both used an empirical relationship, developed by Langbein (1949), between temperature, precipitation, and runoff, as applied to the arid regions of the American southwest. Neither study relied on the use of an atmospheric GCM, except in principle to provide boundary conditions for the temperature and precipitation changes anticipated from a doubling of atmospheric carbon dioxide.

Revelle and Waggoner (1983) examined the effects of a $2^{\circ} \mathrm{C}$ increase in surface air temperature and a $10 \%$ decrease in precipitation in the arid regions of the United States, anticipated in a doubled $\mathrm{CO}_{2}$ climate. Their study used the Langbein relationship in conjunction with their own multiple regression equation relating temperature and precipitation records to the virgin flow of the Colorado River. Use of this equation implied that for the postulated climate change, Colorado River flow would be reduced by $40 \%$, while the $2{ }^{\circ} \mathrm{C}$ increase in temperature alone would lead to a flow decrease of almost $30 \%$. This conclusion agrees closely not only with the Langbein relationship, which would predict a $35 \%$ decrease in runoff for a $2^{\circ} \mathrm{C}$ increase in temperature, but also with the predictions of Stockton and Boggess (1979), which indicate a decrease in water supply of $40 \%-57 \%$ for the same combination of temperature increase and precipitation decrease, in the same region.

Stream flow reductions of such magnitude would result in serious consequences for the Southwest. California relies on the Colorado River for about $15 \%$ of its water; under the predicted scenario, the ratio of water requirements to the mean annual runoff (a measure of water availability) in the Colorado basin would more than double from its present value to a value of 0.83 , severely constraining the availability of water exports from the river (Revelle and Waggoner 1983). Even under the present climate, the ratio of water requirements to supplies is greater than unity for the lower Colorado River, where the deficit is made up using groundwater supplies. Although a more recent study by Nash (1991) indicates that reductions in runoff would be less severe than indicated by the Revelle and Waggoner study $(14 \%-23 \%)$, she still emphasizes the serious impact such a decrease would have on water management in the Southwest. Examples include reductions in water storage, hydroelectric power production, consumptive water use (agriculture, etc.), and water quality. Table 1 quantifies these impacts for a range of flow change scenarios (Nash 1991).

A study conducted by Idso and Brazel (1984) followed the work of Revelle and Waggoner, but added a two-thirds reduction in transpiration to emulate stomatal responses to increased atmospheric $\mathrm{CO}_{2}$. Again using the Langbein relationship between temperature, precipitation, and runoff, Idso and Brazel found that the same combination of a $2^{\circ} \mathrm{C}$ temperature increase and $10 \%$ reduction in precipitation leads to a greater than $40 \%$ increase in stream flow when the transpiration reduction is included. Without assuming any change in precipitation or temperature, the antitranspirant effects alone lead to an $87 \%$ increase in stream flow in the West. Thus, including the transpiration-reducing effects of increased stomatal resistance led to a "very opposite result" than that of the Revelle and Waggoner study, holding everything else constant (Idso and Brazel 1984). Drawing from the conclusions in Table 1, such an increase in stream flow would greatly increase the water resources in the Southwest, implying a very different management strategy.

Our study also applies the Langbein relationship to examine runoff changes. But rather than assuming a range of temperature and precipitation changes, we use those predicted by increasing stomatal resistance in the coupled land-atmosphere GCM. The runoff changes predicted by the Langbein relationship are then compared to the model-predicted runoff changes. 


\section{c. Modeling studies of increased stomatal resistance}

Both of the previous studies have greatly simplified the relationships between temperature, precipitation, and runoff, and have made several assumptions about how these variables would change under a doubling of atmospheric carbon dioxide. Studies incorporating the antitranspirant effect of atmospheric $\mathrm{CO}_{2}$ into coupled land-atmosphere GCMs take the studies to another level, increasing the complexity of the relationships between the variables and adding dynamic feedbacks to the system. A number of assumptions are still required, particularly for the degree to which plants will suppress their transpiration rates. We follow studies that have focused on how a reduction in transpiration will affect global climate.

In particular, Pollard and Thompson (1995) used the National Center for Atmospheric Research's (NCAR) Global Environmental and Ecological Simulation of Interactive Systems GCM coupled with their own land surface transfer scheme to examine the effects of doubled stomatal resistance. Their simulation resulted in a transpiration decrease of $20 \%-50 \%$ and surface air warming of $2^{\circ}-5^{\circ} \mathrm{C}$ in heavily forested areas-including tropical South America, parts of the Northern Hemispheric boreal forests in Canada, and Russia and Siberia in summer-plus a global shifting of precipitation patterns. Although large hydrometeorological changes were found in the areas most affected, on a global average, they found that these changes were small compared to experiments testing the direct climate effect of doubled $\mathrm{CO}_{2}$.

Henderson-Sellers et al. (1995) also examined the effects of doubled stomatal resistance using NCAR's Community Climate Model Version 1, as modified by Henderson-Sellers et al. (1993) (CCM1-Oz) coupled with the Biosphere-Atmosphere Transfer Scheme (BATS) (Dickinson 1984) at both one and two times the current $\mathrm{CO}_{2}$ levels. They found similar results to Pollard and Thompson in their $1 \times \mathrm{CO}_{2}$ study. When the doubled stomatal resistance was combined with a doubling of $\mathrm{CO}_{2}$, similar trends resulted (slight decreases in evaporation; increases in temperature, sensible heat, and total runoff); but the changes in all variables were notably larger, except evaporation, which decreases only marginally in the combined experiment. They emphasized that the combined experiment shows different results than if the two experiments (doubled stomatal resistance and doubled $\mathrm{CO}_{2}$ ) were evaluated separately.

The linking of the stomatal resistance formulations to photosynthetic processes and atmospheric $\mathrm{CO}_{2}$ concentration was subsequently addressed by Sellers et al. (1996), who have included SiB2 (Sellers et al. 1992) in the Colorado State University GCM to compare the radiative and physiological effects of doubled $\mathrm{CO}_{2}$ on climate. Their results indicate that for $2 \times \mathrm{CO}_{2}$ (radiative and physiological) conditions, evapotranspiration would drop and that air temperature would increase over the tropical continents, amplifying the changes resulting from atmospheric radiative effects.

None of the above GCM studies specifically examined how such changes would affect the American southwest. Our study continues these earlier GCM studies using the more recent and improved Community Climate Model version 3 (CCM3) (Kiehl et al. 1996) but attempts to draw conclusions about how these various effects will manifest themselves in the water resource availability in the Southwest. Of particular concern is whether water resources will dramatically increase as a result of adding this stomatal effect, as determined by Idso and Brazel, or whether stomatal effects would be negligible and global warming would in fact seriously constrain water resources, as suggested by Revelle and Waggoner.

\section{Models used to assess stomatal responses}

The present study used NCAR's CCM3 (Kiehl et al. 1996), coupled with two different land surface treatments to examine the effects of doubled stomatal resistance, holding atmospheric $\mathrm{CO}_{2}$ levels constant. The two land surface treatments evaluated are BATS (Dickinson et al. 1986, 1993) and the NCAR Land Surface Model (LSM), developed by Bonan (1996a).

\section{a. Stomatal resistance as described by the BATS model}

Stomatal resistance is defined in the BATS model as a function of solar radiation, leaf temperature, vapor pressure, and soil moisture, and it is computed using the following general formula, based on that of Jarvis (1976):

$$
r_{s}=r_{\mathrm{smin}} R_{f} S_{f} V_{f} M_{f} \quad r_{s} \leq r_{\mathrm{smax}},
$$

where $r_{\text {smin }}$ is the minimum stomatal resistance, $R_{f}$ is the effect of visible radiation on the canopy, $S_{f}$ is the effect of leaf temperature, $V_{f}$ is the effect of vapor pressure deficit, $M_{f}$ is the effect of soil moisture stress, and $r_{\text {smax }}$ is the specified maximum stomatal resistance $(20000 \mathrm{~s}$ $\mathrm{m}^{-1}$ ). The parameter $r_{\text {smin }}$ is specified for each vegetation type by the model input. Detailed equations for each of these parameters are given in the documentation (Dickinson et al. 1986, 1993).

BATS uses the computed $r_{s}$ [from Eq. (1)] as input for the evapotranspiration calculation, which consists of both transpiration from a dry leaf surface, $E_{\mathrm{tr}}$ [Eq. (2)], and evaporation from canopy surface water, $E_{f}$ [Eq. (3)]:

$$
\begin{aligned}
& E_{\mathrm{tr}}=\left(\frac{r_{a l}}{r_{a l}+r_{s}}\right) L_{d} E_{f}^{\text {wet }} \\
& E_{f}=L_{w} E_{f}^{\text {wet }} .
\end{aligned}
$$

Here, $L_{w}$ and $L_{d}$ are the wet and transpiring fractions of the canopy surfaces, respectively; $r_{\mathrm{al}}$ is the aerodynamic 


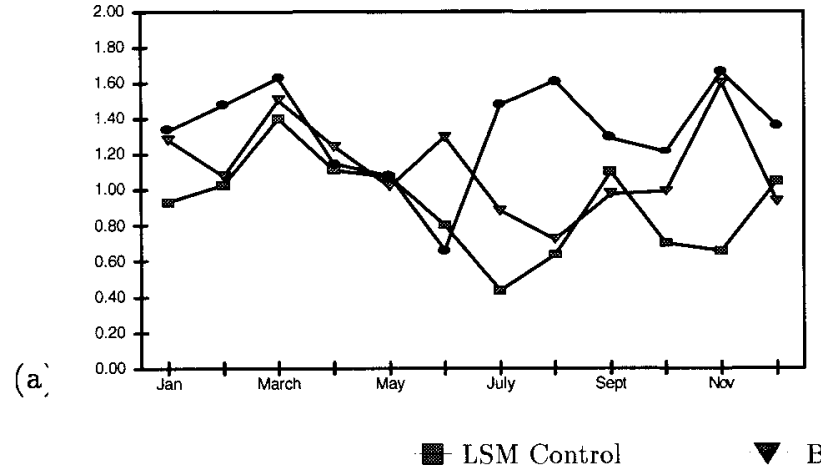

(b)

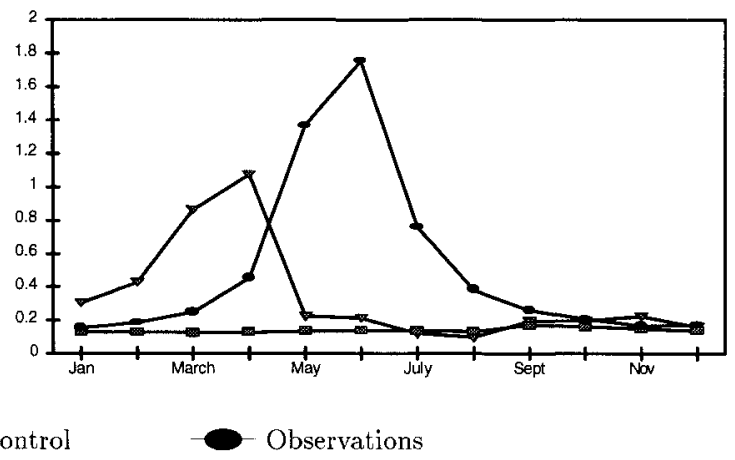

FIG. 1. Model output for the Colorado River basin compared to observational (a) precipitation and (b) runoff. Precipitation data include both rain and snow. Runoff data include surface and subsurface runoff. Units are mm day ${ }^{-1}$ for (a) and (b)

resistance between the leaf surface and the surrounding air; and $E_{f}^{\text {wet }}$ is the value of evaporation from a completely wet surface. Total evapotranspiration, then, is proportional to the sum of Eqs. (2) and (3). As seen by Eq. (2), an increase in the value for stomatal resistance, $r_{s}$, decreases evapotranspiration, as expected. Evapotranspiration is also constrained by the amount of moisture in the soil, so that $E_{\mathrm{tr}}<E_{\mathrm{trc}}$, the maximum soilsustainable transpiration. If $E_{\mathrm{tr}}$ exceeds $E_{\mathrm{trc}}$, then $E_{\mathrm{tr}}$ is set to equal $E_{\text {trc }}$ by a feedback that increases stomatal resistance. These parameters, in turn, are used by the model to compute the water fluxes between the atmosphere and the biosphere.

Evapotranspiration is also a function of aerodynamic resistance. As roughness length increases, aerodynamic resistance becomes less, and stomatal resistance changes can have a proportionally greater effect [(Eq. (2)]. Canopy stomatal resistance, $r_{\mathrm{sc}}$, is proportional to $r_{s}$. For example, Yang et al. (1995) estimated (in their Table 6) that for tropical rain forests, canopy aerodynamic resistance $\left(r_{a}\right)=20 \mathrm{~s} \mathrm{~m}^{-1}$, and canopy stomatal resistance $\left(r_{\mathrm{sc}}\right)=180$ to $250 \mathrm{~s} \mathrm{~m}^{-1}$; and for summertime midlatitude grassland, $r_{a}=150 \mathrm{~s} \mathrm{~m}^{-1}$ and $r_{\mathrm{sc}}=220 \mathrm{~s} \mathrm{~m}^{-1}$. Because of this and the fact that forests have larger leaf area indexes than grasses, evapotranspiration from forests is more sensitive than that from grassland to changes in stomatal resistance.

In the BATS model, the minimum stomatal resistance, $r_{\text {smin }}$, was uniformly doubled in Eq. (1) for all vegetation types. Changing the minimum stomatal resistance proportionally changes the computed total stomatal resistance, $r_{s}$, except that $r_{s}$ is still constrained by the model to remain below the given maximum stomatal resistance. Note that the phrase "doubled stomatal resistance" is loosely defined to refer to the factor of 2 in $r_{\text {smin }}$, which does not necessarily result in a doubled stomatal resistance compared to the control case because the local environmental variables in Eq. (1) also change as a result of doubling $r_{\text {smin }}$.

\section{b. Stomatal resistance as described by the NCAR LSM model}

The NCAR LSM uses a different technique for modeling stomatal resistance. Its physiological approach, a modification of Collatz et al. (1991) (also Sellers et al. 1992), employs more rigorous plant responses than the meteorological approach of the BATS model (Niyogi and Raman 1997). The detailed explanation of Bonan (1996a) is simply summarized as follows. Stomatal responses are computed using the following formula:

$$
\frac{1}{r_{s}}=m \frac{A e_{s}}{c_{s} e_{i}} P_{\mathrm{atm}}+b,
$$

where $r_{s}$ is the stomatal resistance, $m$ is an empirical parameter (taken from Collatz et al. 1991), $A$ is leaf photosynthesis, $c_{s}$ is the $\mathrm{CO}_{2}$ concentration at the leaf surface, $e_{s}$ is the vapor pressure at the leaf surface, $e_{i}$ is the saturation vapor pressure inside the leaf, $P_{\text {atm }}$ is the atmospheric pressure, and $b$ is the minimum stomatal conductance [chosen by Bonan (1996a) such that maximum stomatal resistance $=20000 \mathrm{~s} \mathrm{~m}^{-1}$ ]. Stomatal resistance in this experiment was doubled by introducing a multiple of 0.5 to the first term on the right-hand side of Eq. (4), hence doubling the resistance while still constraining its inverse to the minimum defined by $b$. As in the BATS simulation, atmospheric $\mathrm{CO}_{2}$ concentration was held constant.

Latent heat fluxes in general are computed as the sum of the evaporation from a wet leaf surface and transpiration from sunlit and shaded leaves, where the dry leaf fluxes are inversely proportional to $r_{s}$.

\section{Experimental design}

The NCAR CCM3 (Kiehl et al. 1996) model was run at the standard T42 horizontal spectral resolution, approximately $2.8^{\circ} \times 2.8^{\circ}$, with 18 vertical levels, climatological sea surface temperature, and current $\mathrm{CO}_{2}$ concentration (355 ppm). Resource constraints prohibited this study from examining the effects of doubled 
TABLE 2. BATS vegetation types and their selected parameter values. Values that are not applicable are noted "N/A."

\begin{tabular}{|c|c|c|c|c|c|c|c|}
\hline & Vegetation type & $\begin{array}{l}\text { Minimum } \\
\text { stomatal } \\
\text { resistance } \\
\left(\mathrm{s} \mathrm{m}^{-1}\right)\end{array}$ & $\begin{array}{l}\text { Maximum } \\
\text { fractional } \\
\text { vegetation } \\
\text { cover }(\%)\end{array}$ & $\begin{array}{c}\text { Vegetation } \\
\text { cover } \\
\text { at } 269 \mathrm{~K} \\
(\%)\end{array}$ & $\begin{array}{l}\text { Roughness } \\
\text { length } \\
\text { (m) }\end{array}$ & $\begin{array}{c}\text { Maximum } \\
\text { LAI }\end{array}$ & $\begin{array}{c}\text { Minimum } \\
\text { LAI }\end{array}$ \\
\hline 1 & Crop/mixed farming & 120 & 85 & 25 & 0.06 & 6 & 0.5 \\
\hline 2 & Short grass & 200 & 80 & 70 & 0.02 & 2 & 0.5 \\
\hline 3 & Evergreen needle-leaf & 200 & 80 & 70 & 1 & 6 & 5 \\
\hline 4 & Deciduous needle-leaf & 200 & 80 & 50 & 1 & 6 & 1 \\
\hline 5 & Deciduous broadleaf & 200 & 80 & 50 & 0.8 & 6 & 1 \\
\hline 6 & Evergreen broadleaf & 150 & 90 & 40 & 2 & 6 & 5 \\
\hline 7 & Tall grass & 200 & 80 & 50 & 0.1 & 6 & 0.5 \\
\hline 8 & Desert & N/A & 0 & 0 & 0.05 & 0 & 0 \\
\hline 9 & Tundra & 200 & 60 & 40 & 0.04 & 6 & 0.5 \\
\hline 10 & Irrigated crop & 200 & 80 & 20 & 0.06 & 6 & 0.5 \\
\hline 11 & Semidesert & 200 & 10 & 0 & 0.1 & 6 & 0.5 \\
\hline 12 & Ice cap/glacier & N/A & 0 & 0 & 0.01 & 0 & 0 \\
\hline 13 & Bog/marsh & 200 & 80 & 40 & 0.03 & 6 & 0.5 \\
\hline 16 & Evergreen shrub & 200 & 80 & 60 & 0.1 & 6 & 5 \\
\hline 17 & Deciduous shrub & 200 & 80 & 50 & 0.1 & 6 & 1 \\
\hline 18 & Mixed woodland & 200 & 80 & 60 & 0.8 & 6 & 3 \\
\hline
\end{tabular}

atmospheric $\mathrm{CO}_{2}$ concentrations due to the long spinup time required. Stomatal resistance was uniformly doubled for all vegetated points. Separate control runs were created for each land surface treatment, and then the models were run again with the doubled stomatal re- sistance. The location and type of the global vegetation in each land treatment were based on gridded datasets (Dickinson et al. 1993; Bonan 1996a) and remain unchanged during the integrations. The models were each run for 5 yr. The first year's output was discarded to
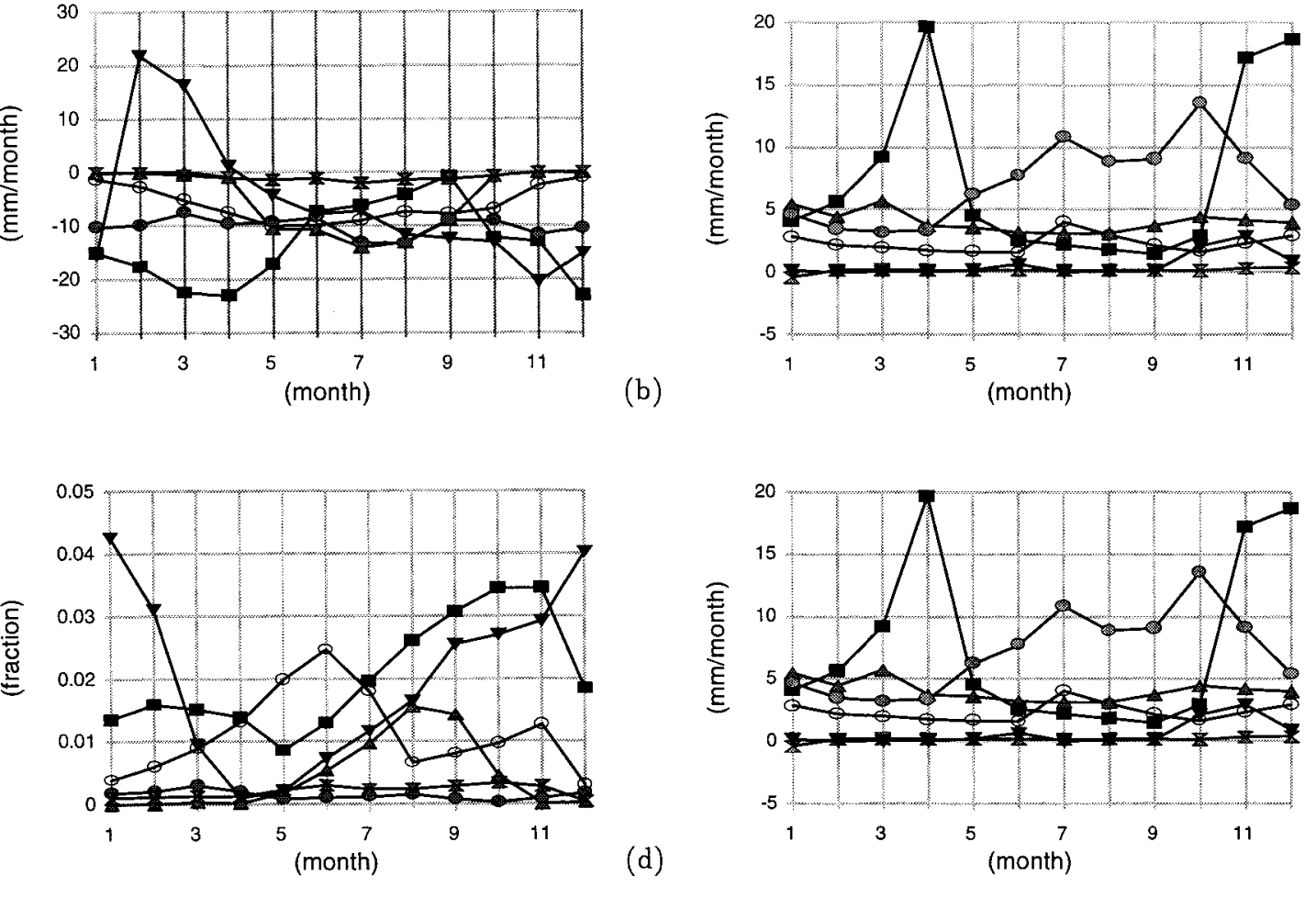

(d)

(b)

(c)

\section{- Short Grass}

A - Evrg. Needleleaf

Evrg. Broadleaf

Tall Grass

- $\mathbf{z}$-Semi-Desert

Evrg. Shrub

FIG. 2. Monthly averaged BATS offline changes (doubled $r_{s}$ case minus control case) due to doubled stomatal resistance for vegetation types short grass, evergreen needle-leaf tree, evergreen broadleaf tree, tall grass, semidesert, and evergreen shrub for variables (a) total evaporation (equals ground and leaf evaporation plus leaf transpiration), (b) Bowen ratio (the ratio of sensible heat flux to latent heat flux), (c) root-zone soil water, and (d) total runoff. 
(a)

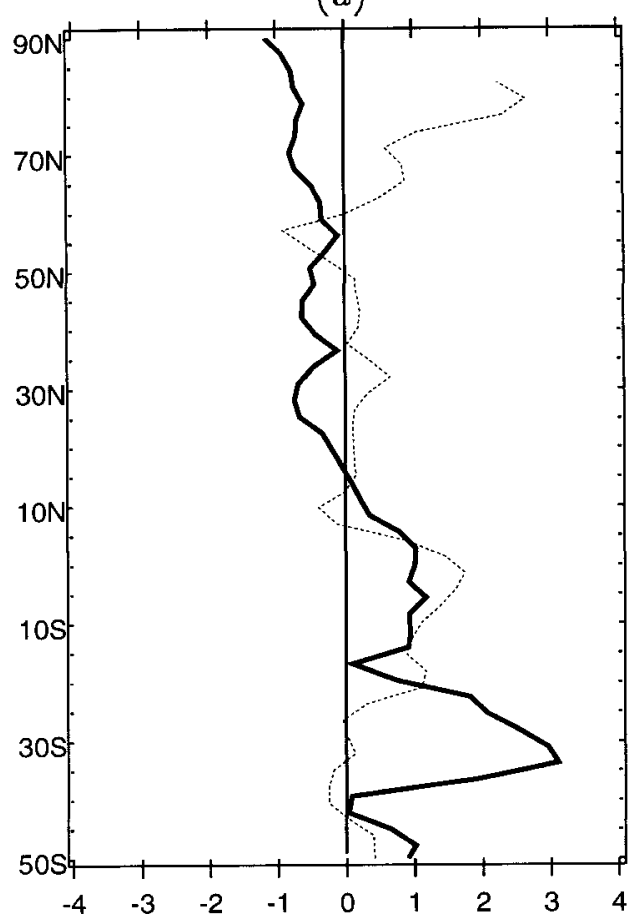

(b)

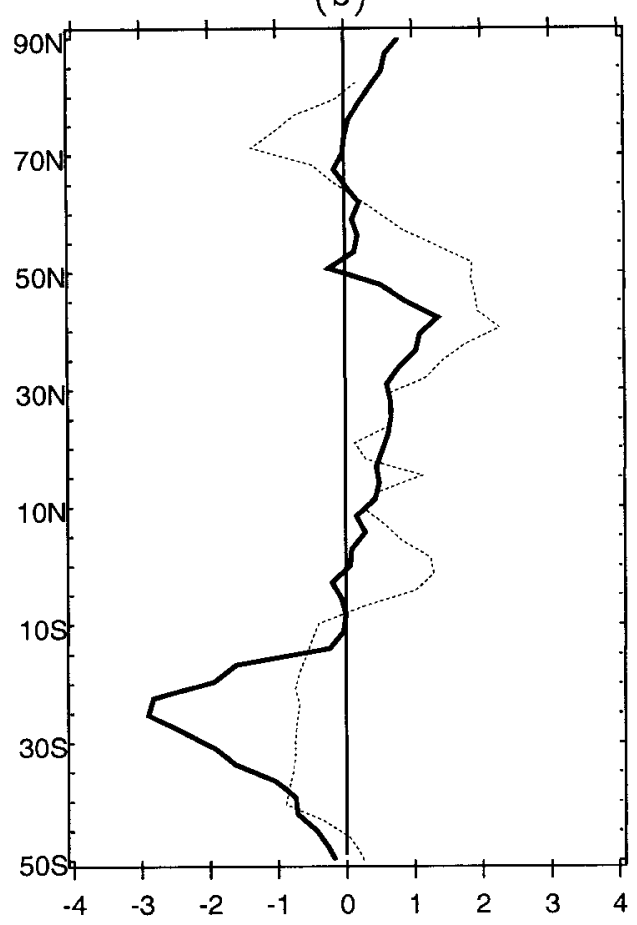

FIG. 3. Zonal mean surface temperature changes (from control; ${ }^{\circ} \mathrm{C}$ ) for all land points for (a) Jan and (b) Jul. BATS model output is solid; LSM model output is dashed.

allow for model spinup, and the last $4 \mathrm{yr}$ were averaged to provide the following results. Our analysis emphasizes the effects of these changes on the hydrological cycle, and how water resources in the southwestern United States may be affected.

The significance levels were determined using a Student's t-test. The 4-yr model output was converted into a set of monthly averages for both the control and the test cases. The null hypothesis that the stomatal doubling and control data for a given region came from the same underlying "population" was tested, assessing the variability of the population from the spatial variability of values within the region. A $t$-test value far enough out on the tails of a standard Gaussian distribution indicates that the null hypothesis can be rejected, meaning that the data for the control and test cases come from different underlying populations, or in other words, that the doubled stomatal resistance results in a significant change. This method does not recognize spatial correlations that may exist within regions, which would lead to less variability within the sample, making any changes appear more significant than they actually are. The more commonly used method would be to look at the collection of monthly or annual output for a given grid point as a sample, in this case with a sample size of four, to determine whether the changes between the control and the test cases are greater than the interannual variability. However, for the small sample size of four, this method also has its drawbacks. Had resources al- lowed us to run the model for a longer period, say 10 yr or more, the common statistical method would have been the appropriate choice. Because the chosen method's limitations might tend to make a region look more, rather than less, significant, and because this paper discusses the lack of significant changes within the region of interest, it is not likely that the limitations of the chosen statistical technique will impact the conclusions of this study. Wigley and Santer (1990) provide a good review of advantages and disadvantages of using any of a suite of statistics. Future work with longer model runs could use the alternate sampling method.

BATS and the NCAR LSM use different methods to calculate stomatal resistance, as well as different parameterizations of the land surface. BATS was the primary model used in this study, and therefore, rather than detailing each of the differences in output that the doubled stomatal resistance caused globally, the NCAR LSM output will only be discussed as it pertains to the western United States.

\section{Model performance}

Control output from a 5-yr run of CCM3-BATS was compared to observed climatic data prepared by Legates and Willmott (1990). Observational data for surface temperature and precipitation were both available and used for comparison to the model output. Overall, the model appears to be too cold by approximately $0.3^{\circ} \mathrm{C}$ 
(a)
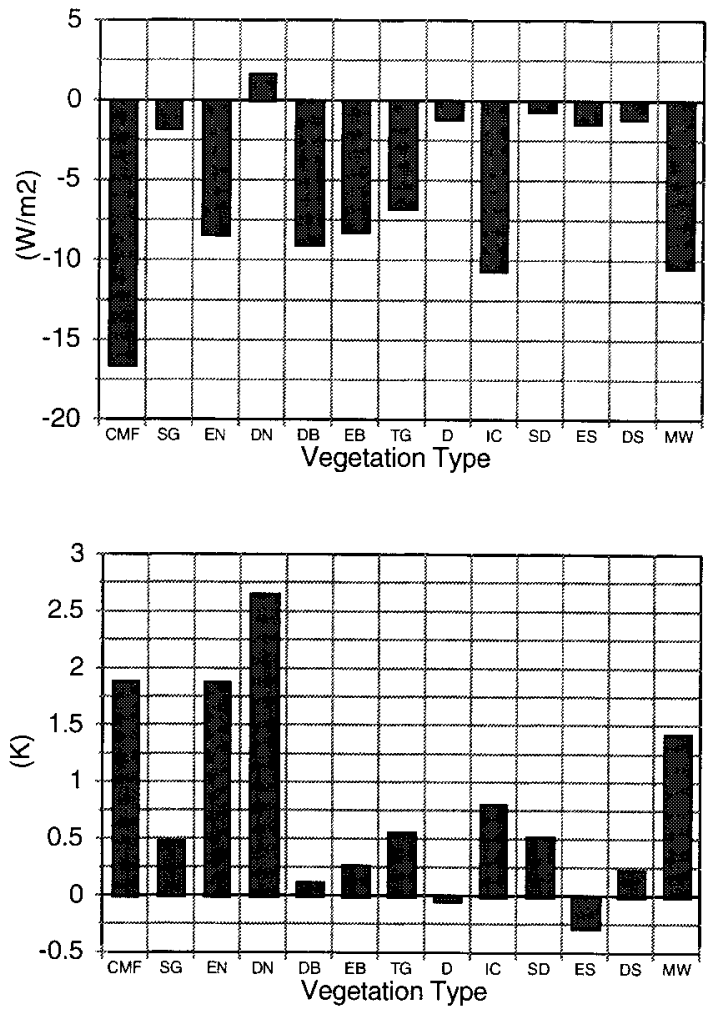

CMF. Crop/Mixed Farming DB.Deciduous Broadleaf IC.Irrigated Crop MW.Mixed Woodland
SG.Short Grass

EB. Evergreen Broadleaf SD.Semi-Desert (b)

(d)
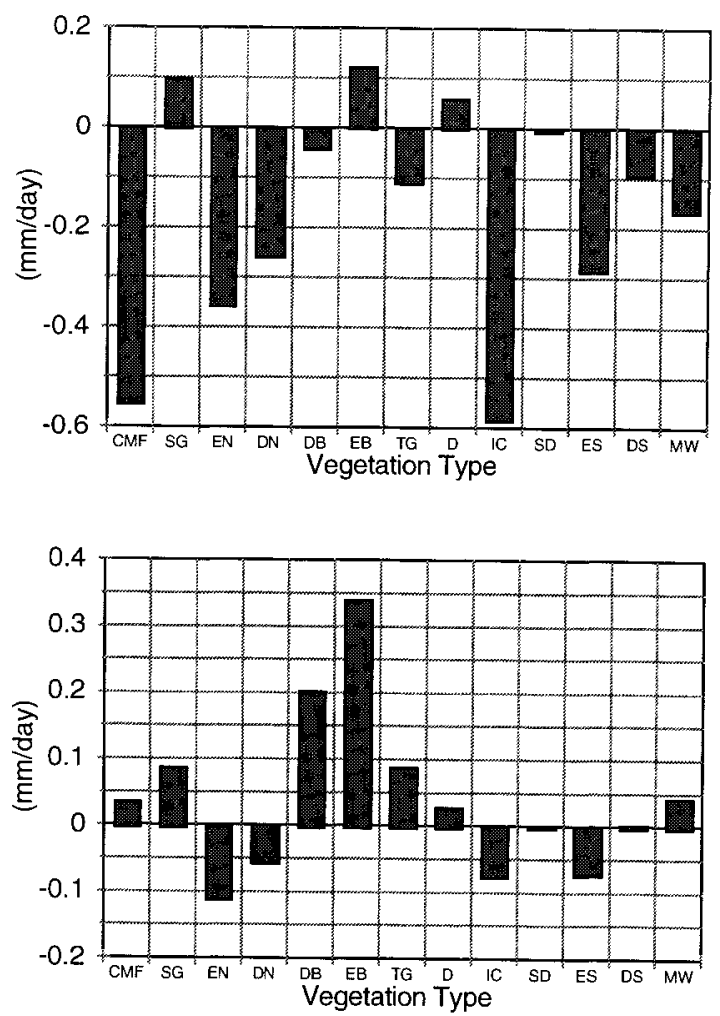
EN.Evergreen Needleleaf
TG.Tall Grass ES.Evergreen Shrub

\author{
DN. Deciduous Needleleaf \\ D.Desert \\ DS. Deciduous Shrub
}

FIG. 4. Global average changes (case minus control) by vegetation type, for BATS model month Jul, for variables (a) latent heat flux, (b) precipitation, (c) surface temperature, and (d) total runoff.

on a global average, and it predicts precipitation within observational uncertainty (higher by up to $0.028 \mathrm{~mm}$ day $^{-1}$ ) globally, with the average over land being in excess by about $5 \%\left(+0.14 \mathrm{~mm} \mathrm{day}^{-1}\right)$.

Precipitation and stream flow data compiled by Wallis et al. (1990) were also available for the Colorado River basin (Morrill 1995) and were used to evaluate the performance of the model on a regional scale. These data were available in a form that could be directly compared to model output without first routing the observational data through a watershed network, because Morrill had already interpolated the gauge data to the mesh of the climate model. Both coupled models emulate observations well for most of the year, with annual average values for precipitation in the basin in the BATS model differing by $0.2 \mathrm{~mm} \mathrm{day}^{-1}$ (observed: $1.33 \mathrm{~mm}$ day $^{-1}$, vs BATS model output: $1.13 \mathrm{~mm}$ day $^{-1}$ ) and by more than $0.4 \mathrm{~mm} \mathrm{day}^{-1}$ in the NCAR LSM model (LSM model output: $0.91 \mathrm{~mm} \mathrm{day}^{-1}$ ). Figure 1 shows that both models underestimate precipitation in the late summer-early fall months. This is apparently in part due to the failure of CCM3 to replicate the Southwest summer monsoon precipitation.
In addition, winter snow accumulation is low compared to that observed, because of the model's flattening of the Rocky Mountains. For these reasons, the modeled midsummer runoff is small by nearly an order of magnitude. The NCAR LSM output does not show any spring or summer peak runoff; BATS runoff peaks in April, rather than June, possibly from premature melting of the model snowpack in mountainous regions due to the model's lack of topographic resolution (Morrill 1995). The combination of these two effects results in annual average values of runoff that differ by close to $0.2 \mathrm{~mm} \mathrm{day}^{-1}$ for the BATS output (observed: 0.51 $\mathrm{mm}$ day $^{-1}$; BATS model output: $0.34 \mathrm{~mm} \mathrm{day}^{-1}$ ) and by almost $0.4 \mathrm{~mm} \mathrm{day}{ }^{-1}$ for the NCAR LSM output (LSM model output: $0.14 \mathrm{~mm} \mathrm{day}^{-1}$ ).

These differences between the control model simulations and observations do not preclude examination of how changes in stomatal resistance will lead to changes in temperature, precipitation, runoff, and other variables. The effects of model bias may be minimized when the perturbation run is compared to the control run. 
(a)

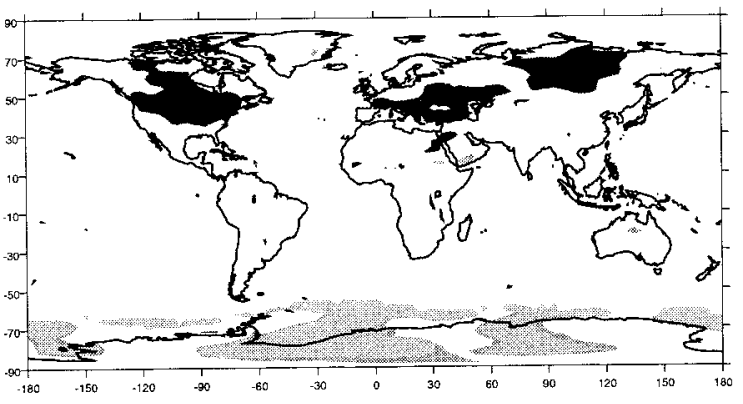

(c)

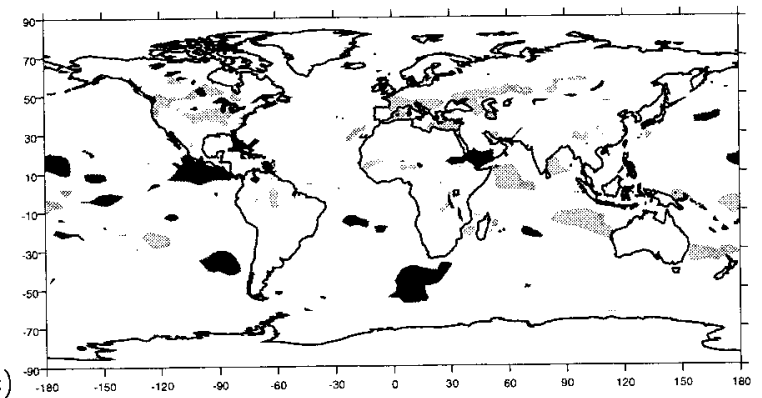

(b)

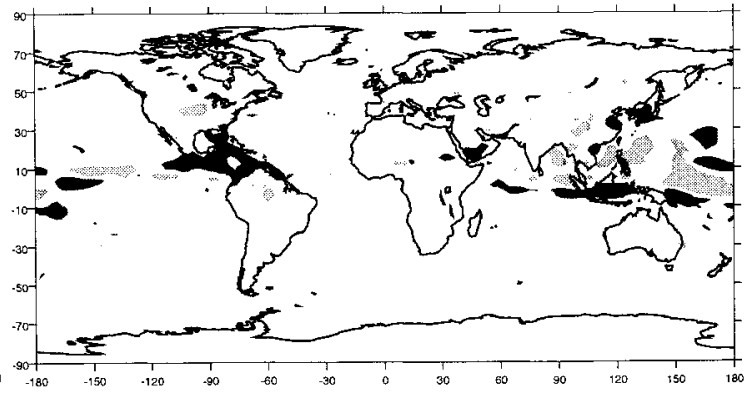

(d)

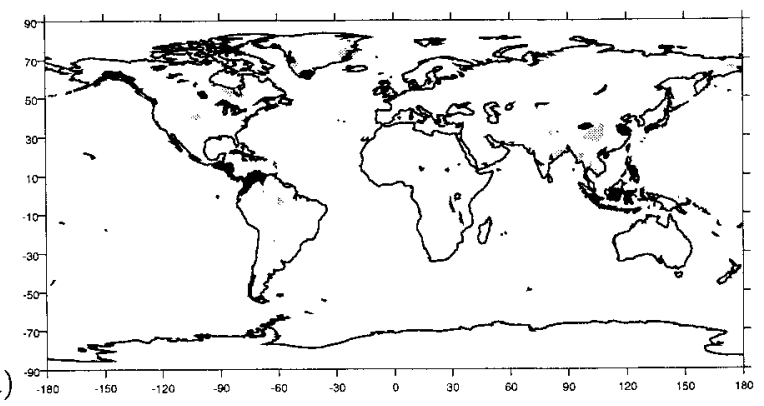

FIG. 5. For model month Jul, statistically significant changes in (a) temperature, (b) precipitation, (c) latent heat flux, and (d) runoff, using the BATS land surface model. Light shading indicates that doubled stomatal resistance caused significant decreases in the variable; dark shading indicates significant increases in the variable—both at the $10 \%$ level.

\section{Analysis}

\section{a. BATS offline analysis}

In order to examine how the coupled CCM3-BATS model is likely to respond to the increased stomatal resistance, the offline version of BATS was run for 10 $\mathrm{yr}$, separately for each of the vegetation types of greatest importance for the analysis in this paper. The offline version was forced with data produced for each model site from a 1-yr CCM version 2 (CCM2)-BATS model run (Shaikh 1996). The vegetation types examined and corresponding local sites are short grass (Tucson, Arizona, at $32^{\circ} 25^{\prime} \mathrm{N}, 111^{\circ} 00^{\prime} \mathrm{W}$ ), evergreen needle-leaf tree
(Port Hardy, Canada, at $50^{\circ} 72^{\prime} \mathrm{N}, 127^{\circ} 48^{\prime} \mathrm{W}$ ), evergreen broadleaf tree (Manaus, Brazil, at $3^{\circ} 02^{\prime} \mathrm{S}, 60^{\circ} 00^{\prime} \mathrm{W}$ ), tall grass (Ndele, Central African Republic, at $8^{\circ} 35^{\prime} \mathrm{N}$, $20^{\circ} 72^{\prime} \mathrm{E}$ ), semidesert (Las Vegas, Nevada, at $36^{\circ} 20^{\prime} \mathrm{N}$, $115^{\circ} 17^{\prime} \mathrm{W}$ ), and evergreen shrub (Charleville, Australia, at $26^{\circ} 27^{\prime} \mathrm{S}, 146^{\circ} 47^{\prime} \mathrm{E}$ ). Important characteristics of each selected land surface type are described in Table 2.

Figure 2 shows the seasonal cycle of total evaporation, Bowen ratio (ratio of sensible heat flux to latent heat flux), root-zone soil moisture (fraction of actual soil moisture out of the maximum soil moisture possible), and runoff responses of the offline model to doubled stomatal resistance for the above-mentioned land-
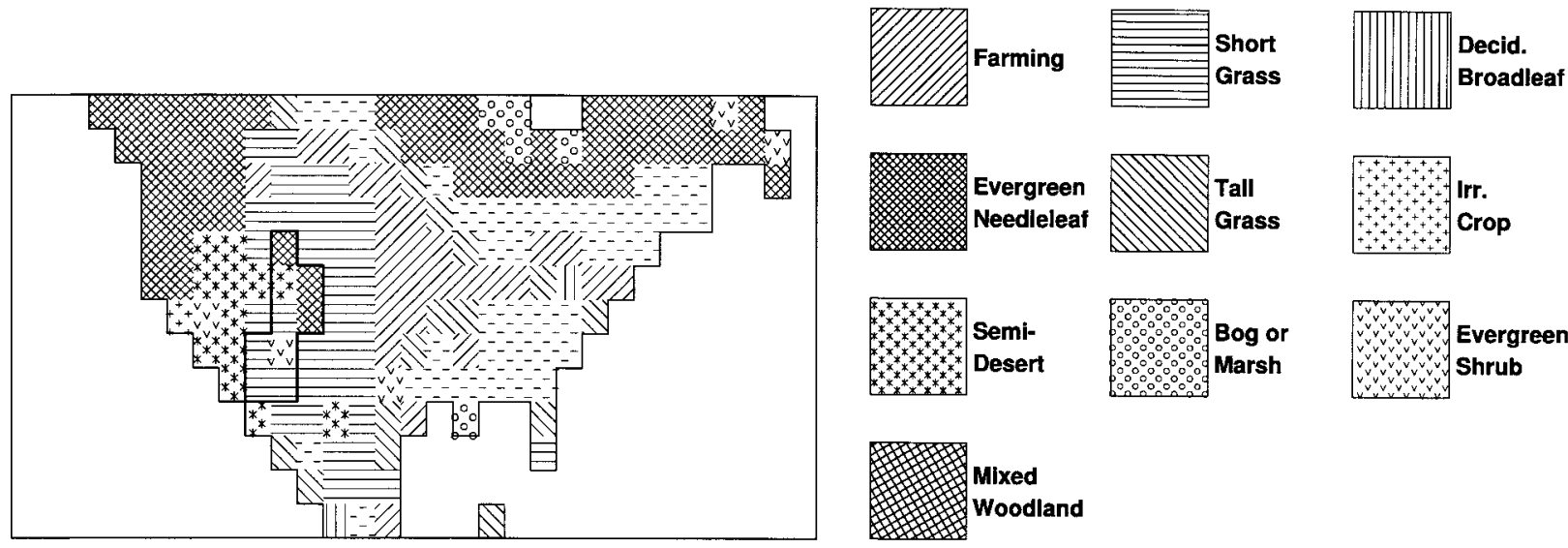

FIG. 6. BATS vegetation types for the United States. The region of the Colorado River basin is outlined. 

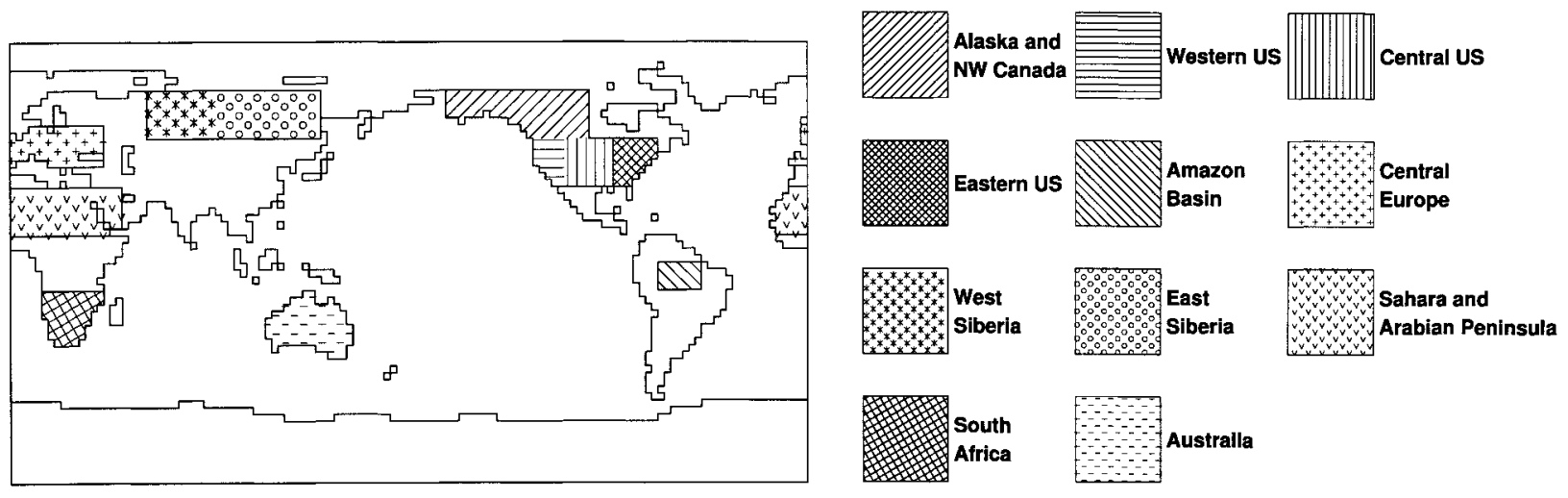

FIG. 7. Geographic regions as described by Bonan (1996b).

cover types. The offline model calculates various other fields, but those illustrated here were chosen to represent the impact of increased stomatal resistance on the hydrological cycle.

The results (Fig. 2) generally show that, in the increased stomatal resistance case, evapotranspiration (evaporation from the leaf surface plus transpiration) and latent heat flux are reduced and sensible heat flux, ground evaporation, soil moisture, and surface runoff increase. Precipitation is prescribed in the offline runs, so precipitation changes must be examined using the coupled BATS-CCM3 model, described later. Effects vary by land-cover type, while types with zero fractional vegetation cover (e.g., desert, water), as expected, exhibit no change at all (figure not shown). The offline analysis gives some indication of what to expect from the coupled atmosphere-land surface model, but these general tendencies may change with the coupling between the land fluxes and a dynamic atmosphere.

Figure 2 shows that changes in stomatal resistance may have little effect in regions with low vegetation cover, such as those characterized as semidesert, but may have large responses for forested regions such as evergreen broadleaf and evergreen needle-leaf (larger roughness length and leaf area index), as noted in other modeling studies (Pollard and Thompson 1995; Henderson-Sellers et al. 1995). Although vegetation with larger roughness length was expected to respond more strongly to changes in stomatal resistance, substantial changes for low roughness length vegetation such as evergreen shrub or short grass are also noted.

\section{b. Global analysis}

In the coupled biosphere-atmosphere experiments, both land surface models show the same trends for each of the variables examined. In agreement with the other GCM studies of doubled stomatal resistance discussed above, latent heat flux is curtailed, leading to increases in sensible heat flux and surface temperature. Precipitation also tends to be decreased as a result of the reduction of water vapor flux from the land surface, and the root-zone soil moisture increases as less water is transpiring through the vegetation.

Global temperature changes (Fig. 3) can be directly compared to Fig. 3 of Sellers et al. (1996). Sellers et al. used SiB2 to examine the physiological effects of 2 $\times \mathrm{CO}_{2}$ concentration on climate. The NCAR LSM and SiB2 employ similar physiological approaches to modeling stomatal responses. The effect of doubling stomatal resistance in our model is most similar to Sellers et al.'s "P" (physiological response to $2 \times \mathrm{CO}_{2}$ only) or "PV" ("down-regulated" physiology resulting from long-term exposure of plants to $2 \times \mathrm{CO}_{2}$ concentrations, while maintaining the same level of net plant photosynthesis as that of $1 \times \mathrm{CO}_{2}$ ) cases. These two cases represent a range of roughly $25 \%-35 \%$ decrease in canopy conductance, which can be directly compared to our doubled stomatal resistance (or $50 \%$ decrease in conductance) as both neglect the radiative effects of doubled $\mathrm{CO}_{2}$ and concentrate solely on the physiological effects. Our NCAR LSM output (Fig. 3) compares well to Sellers et al.'s Fig. 3, with negligible temperature changes in January but July temperature increasing by $+2^{\circ} \mathrm{C}$ between $40^{\circ}$ and $60^{\circ} \mathrm{N}$ for both the NCAR LSM and SiB2 models. The BATS temperature change is somewhat smaller than that of Sellers et al.'s study, in contrast to the previous study by Henderson-Sellers et al. (1995), where using the BATS model gave relatively large temperature increases in this same latitude region.

A closer look at how these changes are evidenced by vegetation type for model month July (using BATSCCM3) is displayed in Fig. 4. Annual changes were separated by vegetation type, and the differences averaged, to determine if any of the same signals seen in the offline analysis were still apparent once the land model was coupled to the atmospheric GCM.

Figure 4 shows the dominant signals that were seen in the offline studies - that is, decreased latent heat flux over land; increases in land surface temperature; and, to a lesser extent, increases in runoff; plus decreased precipitation over land. Of the chosen surface vegetation types, only crop/mixed farming, tall grass, deciduous 
TABLE 3. Description of vegetation types for the western United States, as parameterized by the BATS model. The vegetation parameter values are given in Table 2 .

\begin{tabular}{ccc}
\hline \hline Region & $\begin{array}{c}\text { Total } \\
\text { number } \\
\text { of grid } \\
\text { points }\end{array}$ & $\begin{array}{c}\text { Number of grid points } \\
\text { covered by vegetation } \\
\text { type }\end{array}$ \\
\hline Western United States & 29 & 12 evergreen needle-leaf \\
$\left(30^{\circ}-50^{\circ} \mathrm{N}, 110^{\circ}-130^{\circ} \mathrm{W}\right)$ & & 9 semidesert \\
& & 5 short grass \\
& 1 crop/mixed farming \\
& 1 irrigated crop \\
& 1 evergreen shrub \\
\hline
\end{tabular}

broadleaf tree, and mixed woodland see consistent changes in latent heat flux (decrease), precipitation (decrease), temperature (increase), and runoff (increase). For irrigated crop, the control case simulates negative runoff, implying that water from elsewhere is imported for irrigation. The large negative change in runoff for irrigated crop in Fig. 4d suggests that more irrigation is required to compensate for the reduced precipitation found in the doubled stomatal resistance case. Although reduced evapotranspiration would tend to conserve water and reduce the need for irrigation, the reduced precipitation appears to negate any water savings and, in fact, increase the need for irrigation.

Statistically significant changes in surface temperature, precipitation, latent heat flux, and runoff on a global basis for model month July are shown in Fig. 5 . Strongest signals are generally seen in forested areas, as discussed above, and crop lands. Deciduous and evergreen needle-leaf regions, that is, the boreal forests, see the largest increases in temperature, in agreement with other GCM studies. Deciduous and evergreen broadleaf vegetation, which is primarily in southern Africa and the Amazon basin, shows the largest increase in runoff (Fig. 4), although this does not necessarily translate into statistical significance in Fig. 5. Some changes are seen over the ocean (Fig. 5) due to model variability.
The dominant western U.S. land-cover types, evergreen needle-leaf and semidesert (see Figs. 6 and 7) show very different responses. More than a third of the grid points covering the western United States (12 of 29) are evergreen needle-leaf and slightly less than a third (9 of 29) are semidesert (see Table 3). The evergreen needle-leaf response in Fig. 4 is rather large, particularly for reductions in latent heat flux and precipitation and for increases in temperature. However, semidesert in Fig. 4 shows little or no response. The combination of the two responses should yield signals similar to but smaller than those of evergreen needleleaf, and the dilution of the changes by semidesert may lead to the lack of significance of the changes in this region, discussed next.

\section{c. Regional analysis}

The only statistically significant changes in the western United States occur in June-August (JJA; Table 4), where there is a $31 \%$ decrease in latent heat flux and a $14 \%$ increase in sensible heat flux. Although apparently not statistically significant, temperature and precipitation changes are also greatest in the summer months, as temperature increases by $1.8 \mathrm{~K}$ and precipitation, already minimal in this region of the United States, decreases by just under 35\%, almost twice as much as any other season. For this reason, Northern Hemisphere summer (model month July) was chosen when comparing this region to others (Table 5).

The western United States is compared to selected other geographical regions (defined as in Bonan 1996b) (see Fig. 7) to examine how regions with different dominant vegetation types respond (Table 5). In North America, although no regions exhibited statistically significant temperature changes annually, many exhibit increases during July (see Fig. 8). The central and eastern United States, covered mostly with forests and crops, are strongly affected, with temperature increases of greater than $3 \mathrm{~K}$ and precipitation reductions of over $50 \%$. Temperature also increases in forest-covered Eu-

TABLE 4. Seasonal averaged BATS output for selected variables for the western United States (as defined in Table 3). Upper values represent test case values (doubled stomatal resistance); lower values represent control values. Bold face indicates significant difference at $5 \%$ level; there are no significant differences at $10 \%$ level. Dec-Feb (DJF) etc.

\begin{tabular}{|c|c|c|c|c|c|c|c|}
\hline & $\begin{array}{l}\text { Surface } \\
\text { temperature } \\
(\mathrm{K})\end{array}$ & $\begin{array}{c}\text { Precipitation } \\
\left(\mathrm{mm} \mathrm{day}^{-1}\right)\end{array}$ & $\begin{array}{l}\text { Root-zone } \\
\text { soil water } \\
\quad(\mathrm{mm})\end{array}$ & $\begin{array}{l}\text { Snow, liquid } \\
\text { water } \\
\text { equivalent } \\
(\mathrm{mm})\end{array}$ & $\begin{array}{c}\text { Runoff } \\
\left(\mathrm{mm} \mathrm{day}^{-1}\right)\end{array}$ & $\begin{array}{c}\text { Latent } \\
\text { heat flux } \\
\left(\mathrm{W} \mathrm{m}^{-2}\right)\end{array}$ & $\begin{array}{l}\text { Sensible } \\
\text { heat flux } \\
\left(\mathrm{W} \mathrm{m}^{-2}\right)\end{array}$ \\
\hline DJF & $\begin{array}{l}270.4 \\
271.5\end{array}$ & $\begin{array}{l}3.90 \\
3.35\end{array}$ & $\begin{array}{l}355.8 \\
325.9\end{array}$ & $\begin{array}{l}55.20 \\
45.69\end{array}$ & $\begin{array}{l}1.80 \\
1.52\end{array}$ & $\begin{array}{l}19.8 \\
20.3\end{array}$ & $\begin{array}{l}-13.1 \\
-13.2\end{array}$ \\
\hline MAM & $\begin{array}{l}278.0 \\
278.0\end{array}$ & $\begin{array}{l}2.12 \\
2.12\end{array}$ & $\begin{array}{l}330.9 \\
330.9\end{array}$ & $\begin{array}{l}26.79 \\
26.79\end{array}$ & $\begin{array}{l}1.58 \\
1.64\end{array}$ & $\begin{array}{l}44.6 \\
48.1\end{array}$ & $\begin{array}{l}33.6 \\
28.0\end{array}$ \\
\hline JJA & $\begin{array}{l}294.1 \\
292.3\end{array}$ & $\begin{array}{l}0.43 \\
0.66\end{array}$ & $\begin{array}{l}309.1 \\
290.5\end{array}$ & $\begin{array}{l}0.00 \\
0.00\end{array}$ & $\begin{array}{l}0.23 \\
0.21\end{array}$ & $\begin{array}{l}34.5 \\
50.1\end{array}$ & $\begin{array}{l}93.3 \\
82.2\end{array}$ \\
\hline SON & $\begin{array}{l}280.6 \\
280.4\end{array}$ & $\begin{array}{l}1.67 \\
2.00\end{array}$ & $\begin{array}{l}312.6 \\
287.5\end{array}$ & $\begin{array}{l}8.09 \\
6.16\end{array}$ & $\begin{array}{l}0.40 \\
0.40\end{array}$ & $\begin{array}{l}23.6 \\
27.4\end{array}$ & $\begin{array}{l}21.9 \\
17.2\end{array}$ \\
\hline
\end{tabular}




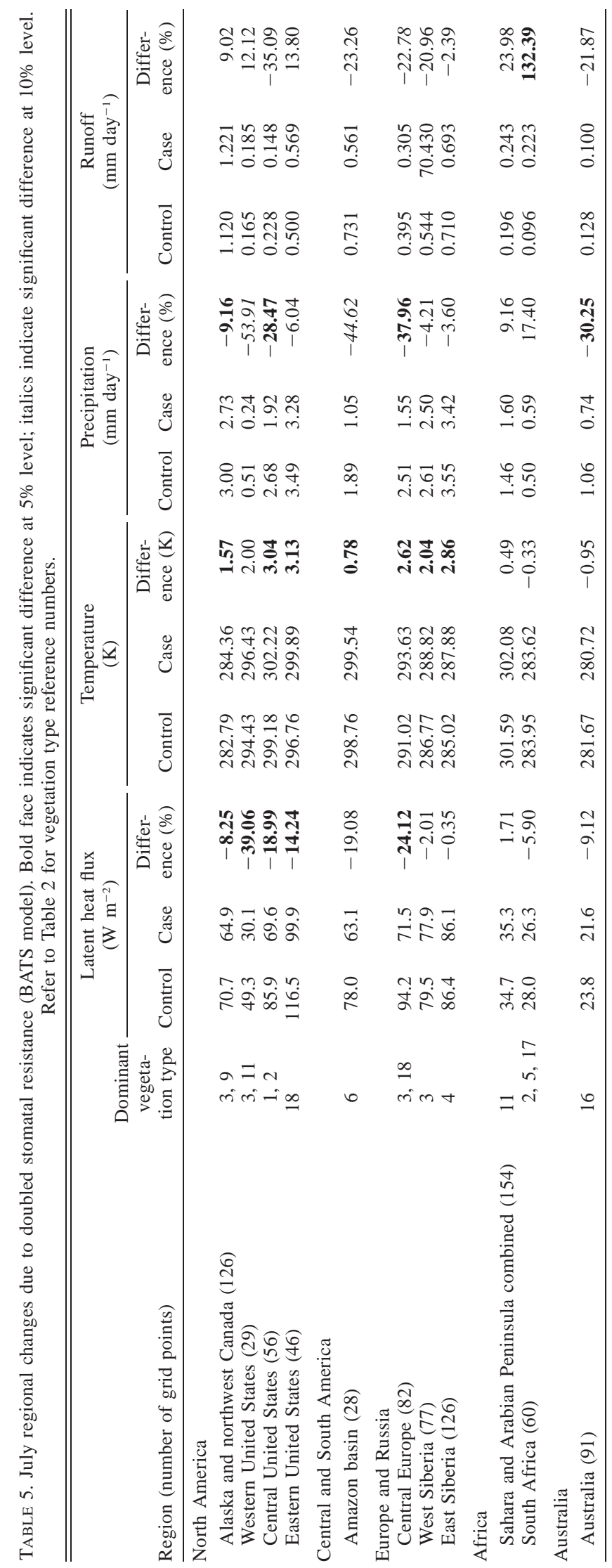


(a)

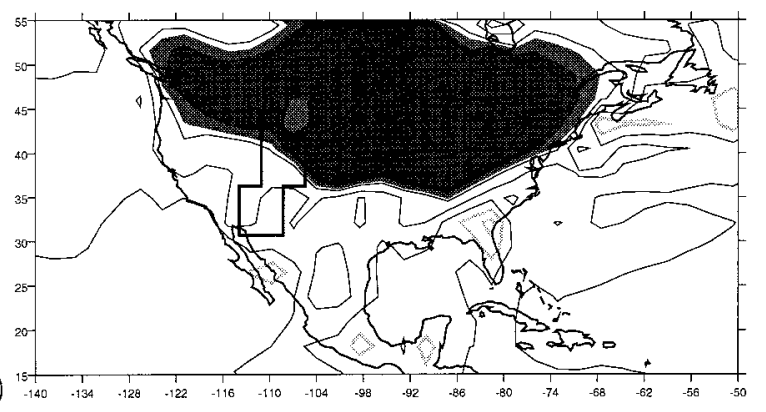

(c)

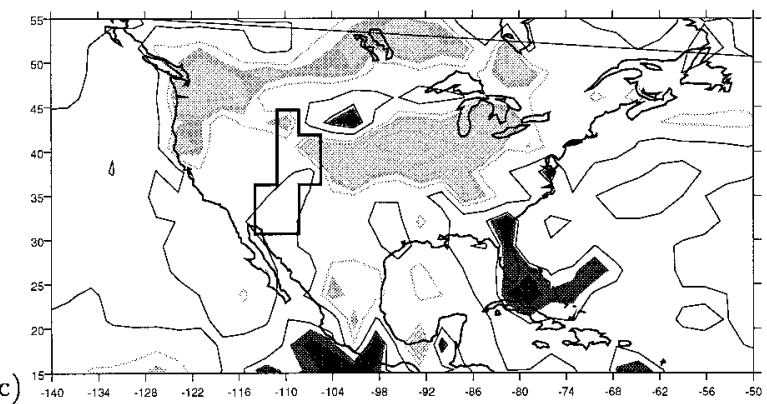

(b)

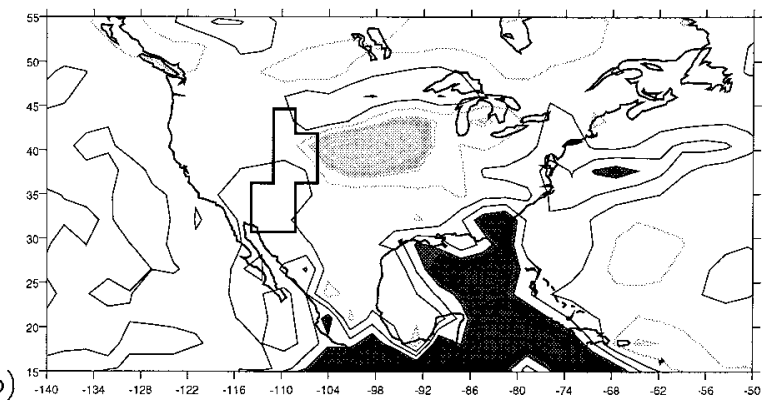

(d)

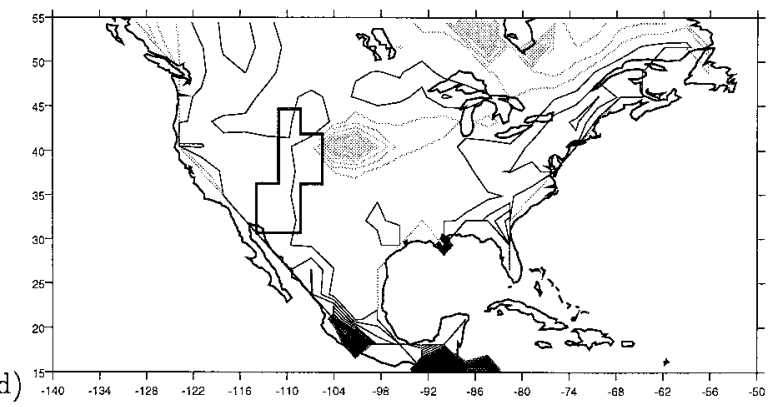

FIG. 8. Same as Fig. 5 except for the United States, with isolines indicating the value of the difference (case minus control) for each parameter. Isolines are set every (a) $1 \mathrm{~K}$, (b) $1 \mathrm{~mm} \mathrm{day}^{-1}$, (c) $20 \mathrm{~W} \mathrm{~m}^{-2}$, and (d) $0.2 \mathrm{~mm} \mathrm{day}^{-1}$. Model month Jul. The region of the Colorado River basin is outlined.

rope and Russia; central Europe's precipitation decreases almost $40 \%$. Precipitation is strongly reduced in Australia and the Amazon basin, and the Amazon also sees temperature increases of $0.8 \mathrm{~K}$. Runoff is significantly increased in South Africa and decreased in Europe. Table 5 shows no significant runoff changes in the regions of the United States, although there are indications that runoff would increase in the western United States.

The western United States shows statistically significant decreases in both latent heat flux and precipitation, and increases, though not statistically significant, in both temperature and runoff. Trends for each of these variables are in agreement with the rest of North America, suggesting that although almost a third of the western United States is sparsely vegetated semidesert, the impacts of a global doubling of stomatal resistance are not localized to a specific vegetated grid point but may become more homogenized to larger geographic regions (see Fig. 8). A large region such as the Sahara and the Arabian Peninsula combined, which contains 154 grid points, compared to a total of 29 for the western United States, has a much larger fraction of sparsely vegetated semidesert and desert (99 grid points), which could account for the lack of significant changes in the Sahara caused by doubled stomatal resistance.

\section{d. Colorado River basin analysis}

As discussed above, the Colorado River basin supplies much of the water resources for the southwestern
United States, including Arizona, Colorado, New Mexico, Utah, Wyoming, California, and Nevada. Nearly 25 million people are served by Colorado River water. In the lower Colorado River basin, the majority of the water is allotted to California, about a third less is currently used by Arizona, and a small amount goes to Nevada. However, under the current system, delivery of the water is contingent upon its availability, meaning that if the water resources out of the Colorado River basin diminish, allotments may have to be redivided. Even aside from such questions of ownership, any significant changes in water availability due to climate change would have serious consequences, as already mentioned above. Therefore, in addition to looking at changes stomatal resistance could have on the western United States, we chose also to look specifically at the Colorado River basin.

The Colorado River basin as parameterized by the BATS model is described in Table 6 and shown in Fig. 6. It shows only two significant changes with the BATS model, a $42 \%$ increase in winter precipitation and a $64 \%$ increase in winter runoff (Table 7). Although not statistically significant, the model also predicts a $40 \%$ decrease in summer runoff. Together the seasonal changes average out to a $12 \%$ increase in annual runoff. This would correspond to an $11 \%-16 \%$ increase in actual flow, according to Table 1. The coupled NCAR LSM model shows no significant changes in runoff, or any other variable, for this region, although it also indicates 
TABLE 6. Description of vegetation types for the Colorado River basin, as parameterized by the BATS model. The Colorado River basin is defined as the nine model grid points centered at $32.0^{\circ}-$ $34.8^{\circ} \mathrm{N}, 112.5^{\circ} \mathrm{W} ; 32.0^{\circ}-43.2^{\circ} \mathrm{N}, 109.7^{\circ} \mathrm{W}$; and $37.6^{\circ}-40.4^{\circ} \mathrm{N}$, $106.9^{\circ} \mathrm{W}$. See Table 2 for vegetation parameter values.

\begin{tabular}{ccc}
\hline \hline Region & $\begin{array}{c}\text { Total } \\
\text { number } \\
\text { of grid } \\
\text { points }\end{array}$ & $\begin{array}{c}\text { Number of grid } \\
\text { points covered } \\
\text { by vegetation } \\
\text { type }\end{array}$ \\
\hline Colorado River basin & 9 & $\begin{array}{l}\text { 4 short grass } \\
\text { 3 evergreen needle-leaf } \\
1 \text { evergreen shrub } \\
1 \text { semidesert }\end{array}$ \\
\hline
\end{tabular}

increased temperatures and runoff throughout the year, as well as increases in winter and summer precipitation. Soil water in the coupled NCAR LSM model increases in all seasons except winter. A closer look at how selected variables change on a monthly basis can be seen in Fig. 9.

Because predicting runoff values is still problematic in GCMs, regardless of the land surface model, we also used the Langbein relationship in conjunction with model predictions for changes in surface temperature and precipitation to calculate runoff values for the Colorado River region and the western United States. This relationship is simply an empirical relationship relating runoff changes to changes in surface air temperature, precipitation, or both, and has not been modified in order to apply it here. To the extent that the Langbein relationship is satisfied by the GCM, it can provide the runoff resulting from model climate change, excluding the direct effect of stomatal closure on soil water budgets. We use the relationship in a manner similar to Idso and Brazel, by using the GCM to determine how stomatal changes affect surface temperature and precipitation, but then we use the Langbein relationship to provide an alternative determination as to how runoff will respond. In order to apply this relationship, annual average surface temperatures from the model output were converted into weighted mean annual temperatures by dividing the sum of the products of average monthly temperature and precipitation by the mean annual precipitation. For the surface temperatures weighted in this way, the annual average temperature for the Colorado River basin decreases, although it increased by $0.5 \mathrm{~K}$ when all months were weighted equally.

Surface temperature and precipitation changes for the Colorado River basin were taken from the model output and evaluated according to the Langbein relationship, as used by Idso and Brazel and also Revelle and Waggoner. The empirical relationship used in their studies was extrapolated to apply to our specific data. This relationship is presented graphically in Fig. 10.

As shown in Table 8, the runoff trends predicted by BATS and the NCAR LSM agree with the trends obtained using Langbein's relationship. However, the magnitudes are at some points drastically different. For the western United States, the empirical relationship predicts runoff changes of $-6 \%$ and $+7 \%$ for the NCAR LSM and BATS, respectively. For the Colorado River basin, the changes are $+20 \%$ and $+7 \%$, respectively. The $20 \%$ increase predicted by the Langbein relationship using the NCAR LSM output is a relatively small

TABLE 7. Seasonal averaged output for selected variables for the Colorado River basin from (a) the BATS model and (b) the LSM model. Upper values represent test case values (doubled stomatal resistance); lower values represent control values. Bold face indicates significant difference at 5\% level; italics indicate significant difference at $10 \%$ level.

\begin{tabular}{|c|c|c|c|c|c|c|}
\hline & $\begin{array}{l}\text { Surface } \\
\text { temperature } \\
(\mathrm{K})\end{array}$ & $\begin{array}{c}\text { Precipitation } \\
\left(\mathrm{mm} \mathrm{day}^{-1}\right)\end{array}$ & $\begin{array}{l}\text { Root-zone } \\
\text { soil water } \\
\quad(\mathrm{mm})\end{array}$ & $\begin{array}{c}\text { Runoff } \\
\left(\mathrm{mm} \mathrm{day}^{-1}\right)\end{array}$ & $\begin{array}{c}\text { Latent } \\
\text { heat flux } \\
\left.(\mathrm{W} \mathrm{m})^{-2}\right)\end{array}$ & $\begin{array}{l}\text { Sensible } \\
\text { heat flux } \\
\left(\mathrm{W} \mathrm{m}^{-2}\right)\end{array}$ \\
\hline \multicolumn{7}{|l|}{ (a) } \\
\hline DJF & $\begin{array}{l}269.8 \\
269.9\end{array}$ & $\begin{array}{l}1.56 \\
1.10\end{array}$ & $\begin{array}{l}270.42 \\
241.86\end{array}$ & $\begin{array}{l}0.18 \\
0.11\end{array}$ & $\begin{array}{l}23.3 \\
21.5\end{array}$ & $\begin{array}{r}-0.1 \\
0.9\end{array}$ \\
\hline MAM & $\begin{array}{l}279.4 \\
279.5\end{array}$ & $\begin{array}{l}1.18 \\
1.25\end{array}$ & $\begin{array}{l}272.73 \\
252.33\end{array}$ & $\begin{array}{l}0.28 \\
0.26\end{array}$ & $\begin{array}{l}40.4 \\
43.4\end{array}$ & $\begin{array}{l}64.6 \\
59.7\end{array}$ \\
\hline JJA & $\begin{array}{l}298.5 \\
296.8\end{array}$ & $\begin{array}{l}0.73 \\
0.97\end{array}$ & $\begin{array}{l}244.96 \\
217.54\end{array}$ & $\begin{array}{l}0.03 \\
0.05\end{array}$ & $\begin{array}{l}36.6 \\
42.8\end{array}$ & $\begin{array}{l}95.0 \\
94.1\end{array}$ \\
\hline SON & $\begin{array}{l}282.4 \\
281.9\end{array}$ & $\begin{array}{l}1.10 \\
1.19\end{array}$ & $\begin{array}{l}242.13 \\
207.78\end{array}$ & $\begin{array}{l}0.07 \\
0.08\end{array}$ & $\begin{array}{l}29.6 \\
25.7\end{array}$ & $\begin{array}{l}34.7 \\
36.0\end{array}$ \\
\hline \multicolumn{7}{|l|}{ (b) } \\
\hline DJF & $\begin{array}{l}271.6 \\
271.1\end{array}$ & $\begin{array}{l}1.15 \\
1.00\end{array}$ & $\begin{array}{l}0.205 \\
0.207\end{array}$ & $\begin{array}{l}0.14 \\
0.13\end{array}$ & $\begin{array}{l}12.5 \\
13.9\end{array}$ & $\begin{array}{l}12.3 \\
12.7\end{array}$ \\
\hline MAM & $\begin{array}{l}282.2 \\
281.9\end{array}$ & $\begin{array}{l}1.00 \\
1.19\end{array}$ & $\begin{array}{l}0.214 \\
0.211\end{array}$ & $\begin{array}{l}0.14 \\
0.13\end{array}$ & $\begin{array}{l}36.0 \\
40.5\end{array}$ & $\begin{array}{l}73.5 \\
69.4\end{array}$ \\
\hline JJA & $\begin{array}{l}299.2 \\
297.6\end{array}$ & $\begin{array}{l}0.86 \\
0.62\end{array}$ & $\begin{array}{l}0.167 \\
0.160\end{array}$ & $\begin{array}{l}0.16 \\
0.14\end{array}$ & $\begin{array}{l}35.9 \\
29.6\end{array}$ & $\begin{array}{r}97.6 \\
104.7\end{array}$ \\
\hline SON & $\begin{array}{l}293.7 \\
282.4\end{array}$ & $\begin{array}{l}0.69 \\
0.82\end{array}$ & $\begin{array}{l}0.167 \\
0.163\end{array}$ & $\begin{array}{l}0.18 \\
0.16\end{array}$ & $\begin{array}{l}18.7 \\
20.3\end{array}$ & $\begin{array}{l}39.3 \\
40.0\end{array}$ \\
\hline
\end{tabular}



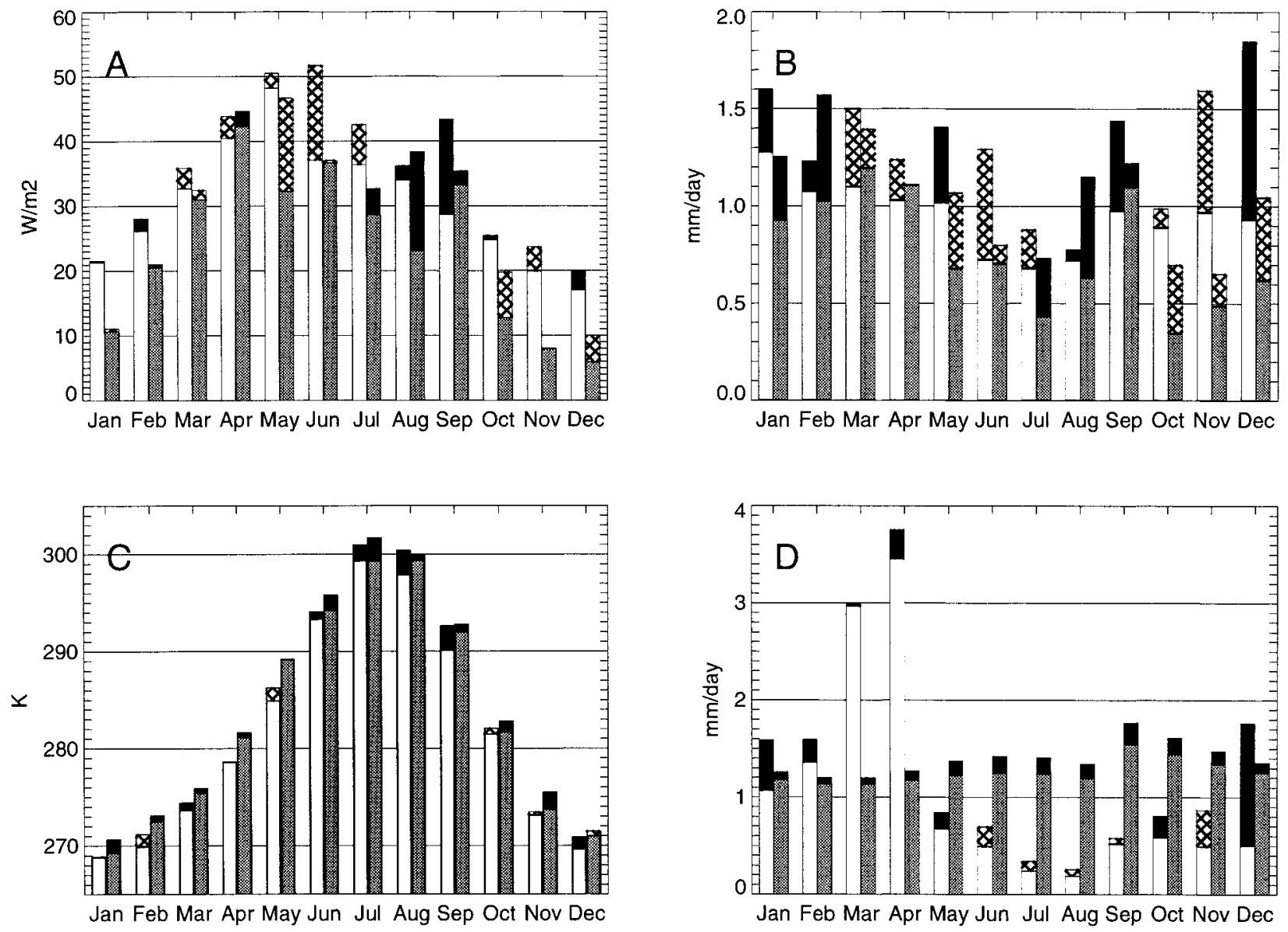

FIG. 9. Annual cycle of Colorado River basin changes caused by doubled stomatal resistance for the variables (a) latent heat flux, (b) precipitation, (c) surface temperature, and (d) total runoff. BATS output values are shown in white; LSM output values are gray. For both models, if the test case values are higher, indicating that the doubled stomatal resistance caused an increase, the difference is shown in black; if the control values are higher, indicating that the doubled stomatal resistance caused a decrease, the difference is shown in hatched shading.

$0.01 \mathrm{~mm} \mathrm{day}^{-1}$, which is the same magnitude as the NCAR LSM model-predicted change, but represents a larger percent increase because the Langbein relationship predicts much lower values of runoff for both the case and the control.

Because only the BATS model exhibits statistically significant differences in temperature or precipitation in this region, its changes in predicted runoff are more likely to be meaningful. The annual, seasonal, and July temperature and precipitation changes for the western United States and the Colorado River basin are not statistically significant using the NCAR LSM. The estimate of runoff change using this method and BATS model output is $7 \%$ for both regions. According to Table 1, this corresponds to roughly a $7 \%$ increase in stream flow. However, establishing the statistical significance of this number is problematic.

\section{Discussion}

The results of our research agree qualitatively with other doubled stomatal resistance experiments. Sensible heat, surface temperature, and root-zone soil moisture increase, and evaporation and precipitation decrease. The strongest effects are seen in forest areas due to their low aerodynamic resistance and high leaf area index, which is also in agreement with other doubled stomatal resistance studies. The changes in runoff and stream flow in the western United States or the Colorado River basin are small or negligible. Although the model runs were each only $5 \mathrm{yr}$, the use of the newer GCM, CCM3 (which incorporates improved hydrological and radiative processes relative to $\mathrm{CCM} 2$ ), may add some strength to our study relative to the previous GCM studies of stomatal effects. Running the model for $10 \mathrm{yr}$ or longer would strengthen our statistical analysis but in qualitative terms would not be expected to change our result due to the agreement between our results and earlier studies performed with longer model runs [e.g., Sellers et al. (1996): $30 \mathrm{yr}$; Pollard and Thompson (1995): $10 \mathrm{yr}]$.

Our results for the Colorado River basin are in agreement with a study done by Skiles and Hanson (1994), 


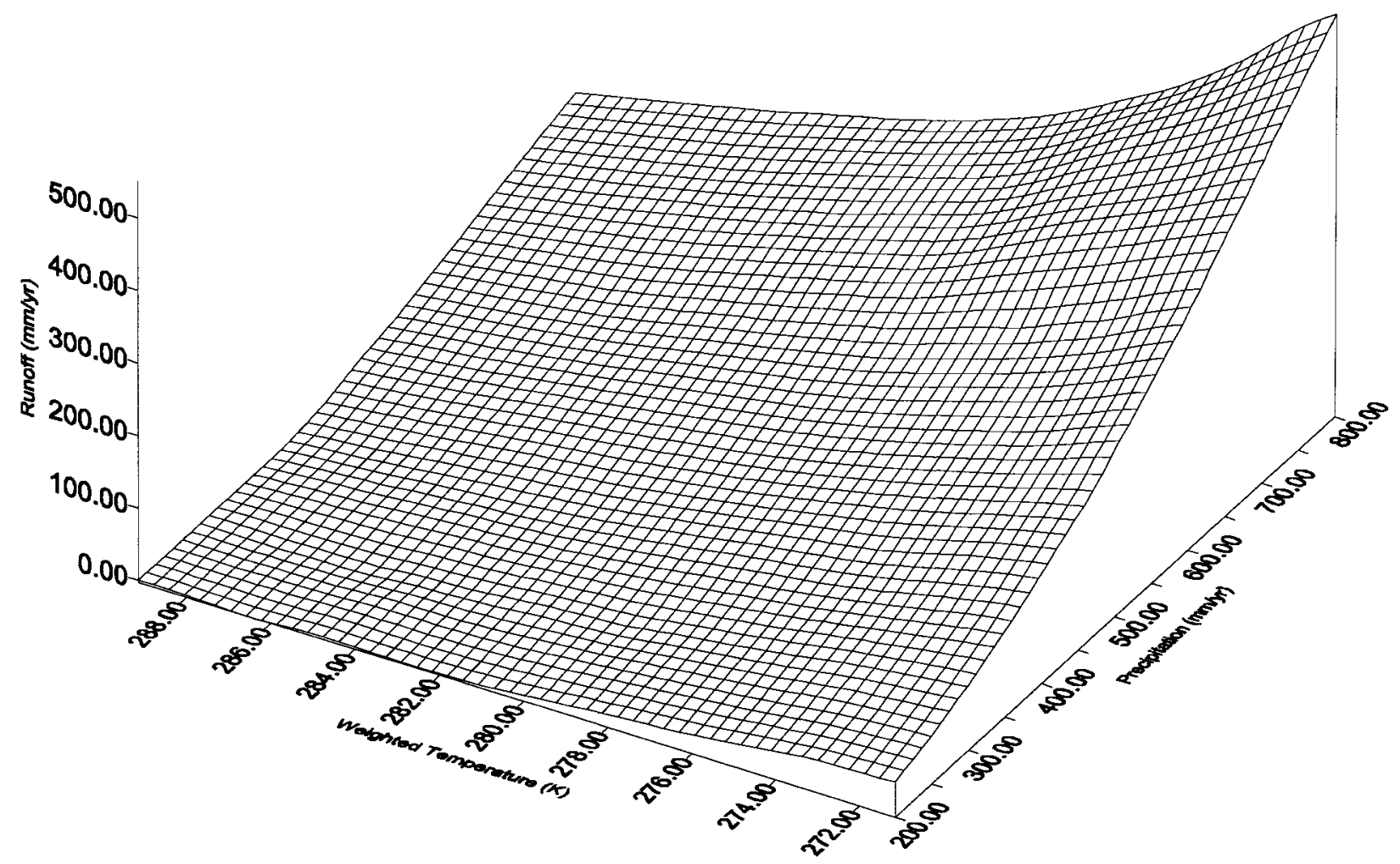

FIG. 10. Empirical relationship between precipitation-weighted annual temperature, annual precipitation, and annual runoff for arid regions. Adapted from Langbein (1949).

who used the same climate scenarios and a one-third reduction in transpiration as did the Idso and Brazel study. However, rather than examining an empirical relationship to determine runoff changes, they used a complex ecosystem scale model to simulate the effects of climate change on water budgets in three watersheds in the western United States. Because Skiles and Hanson's scenarios only examined precipitation changes of $10 \%$ or temperature changes of $2^{\circ} \mathrm{C}$, our BATS output for the Colorado River basin (BATS-C), which resulted in comparatively minimal changes in temperature and precipitation, compares more closely to their scenario 5, which included only the antitranspirant effect, without any changes in temperature or precipitation. Their scenario 5 resulted in runoff increases of around $10 \%$, while our BATS-C scenario resulted in a $16.7 \%$ model-predicted runoff increase or a $7.1 \%$ empirically predicted (using BATS-C model output values for temperature and precipitation as input to the Langbein relationship, neglecting further antitranspirant effects) runoff increase. Our NCAR LSM output for the Colorado River basin (LSM-C) can be compared to their scenario 7, which assumed the antitranspirant effect together with a $2^{\circ} \mathrm{C}$ temperature increase and no change in precipitation, and predicted runoff increases below 10\%. The LSM-C model-predicted runoff increase compares well with theirs, at $7.1 \%$, but our empirically predicted value (using LSM-C model output values for temperature and precipitation) of $20 \%$ is much higher than they predicted.

Thus, although runoff changes could not be shown to be statistically significant for the Colorado River basin or the western United States using the GCMs, use of the empirical relationship indicates a slight runoff increase due to model-predicted increases in precipitation. Because our doubled $r_{s}$ resulted in increased precipitation, we found increased runoff. Decreases in runoff resulted only when the doubled $r_{s}$ caused temperature increases together with precipitation decreases (our LSM-W case), which was in fact the temperature and precipitation scenario that Skiles and Hanson, along with Idso and Brazel, and Revelle and Waggoner, inferred from the $2 \times \mathrm{CO}_{2}$ climate change. Hence, including the latter would be expected to move our result to runoff decreases.

\section{Conclusions}

This study examines the impact of doubled stomatal resistance on water resources, particularly in the western United States and the Colorado River basin. Previous studies of the western United States have indicated $\mathrm{CO}_{2}-$ induced global warming may cause water resources in the region to increase (Idso and Brazel 1984) or decrease (Revelle and Waggoner 1983). Our research asks whether a global increase in stomatal resistance can signifi- 


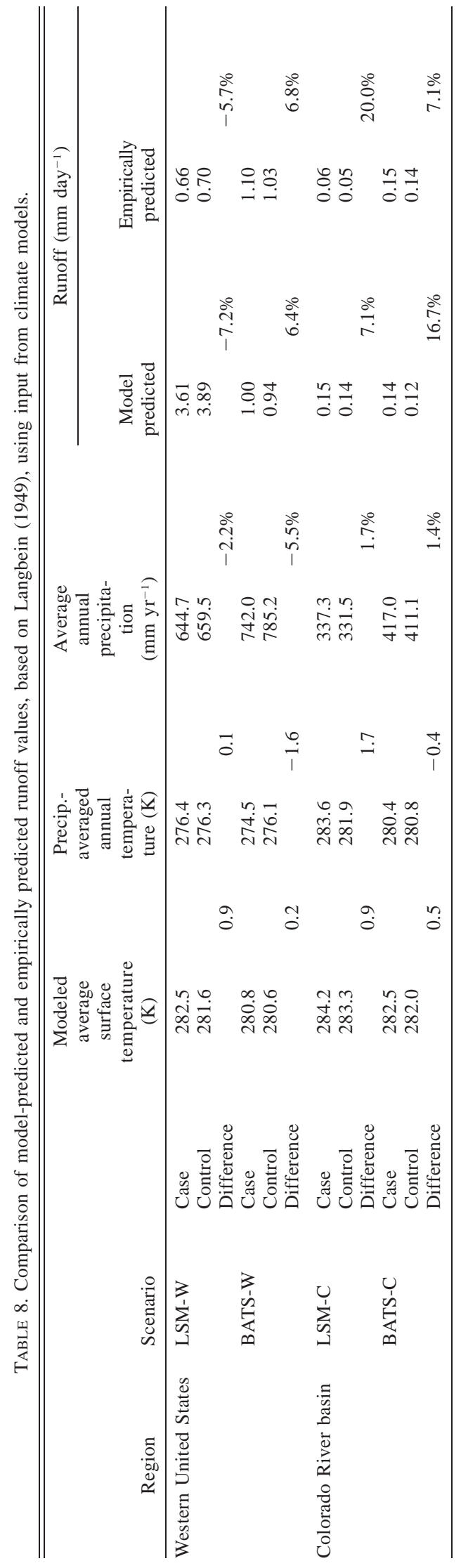

cantly add to the water resources that would otherwise be lost due to the increases in temperature and decreases in precipitation that are anticipated in a doubled $\mathrm{CO}_{2}$ climate.

Using runoff as a measure of water availability, we ran NCAR's CCM3 coupled to both the NCAR LSM and BATS land surface models, both with doubled stomatal resistance. We find no statistically significant changes in the annual runoff of the Colorado River basin for either model; winter runoff is increased at the $10 \%$ significance level in the BATS model. Increased runoff is predicted by both models for the Colorado River basin and the western United States, but the predicted increases (maximum 17\%) are not large enough to overcome the decreases in runoff that have been predicted for a doubled $\mathrm{CO}_{2}$ climate (up to $40 \%$; Revelle and Waggoner 1983). Computing runoff changes using the empirical relationship that was used by Revelle and Waggoner and by Idso and Brazel led to similar results.

This study examined the sensitivity of the models to changes in stomatal resistance, while holding $\mathrm{CO}_{2}$ levels and leaf area indexes (LAI) constant. Should increased photosynthesis lead to increases in LAI, any effects of reduced stomatal resistance on a per unit leaf area basis could be counterbalanced by the increased leaf area. Interactive carbon routines are needed in general to add realism to simulations of vegetation and evapotranspiration, to investigate additional effects of increased photosynthesis and/or LAI on transpiration and water use. In addition, the changes assumed for stomatal resistance were not intended to be representative of the responses of vegetation to climate change. Vegetation responses are likely to vary widely in a doubled $\mathrm{CO}_{2}$ environment; some may even respond by decreasing their stomatal resistance. However, it is anticipated that many types of vegetation will, in fact, increase their stomatal resistance, and so it is important to examine what effect this could have on climate. From this and other studies, it is apparent that stomatal responses to climate changes must be understood for discussions of global climate change and must be included explicitly in climate models.

Acknowledgments. Thanks to Steve Leavitt and Rong Fu for their time and input, Andrea Hahmann for technical assistance, Cas Sprout for the final editing of this paper, and Lisa Graumlich and the Institute for the Study of Planet Earth for fellowship support. Help on details was provided by Jean Morrill, Muhammad Shaikh, and Mike Leuthold. Funding for this study was provided in part by the National Science Foundation under Grant ATM-9419715.

\section{REFERENCES}

Bazzaz, F. A., and E. D. Fajer, 1992: Plant life in a $\mathrm{CO}_{2}$-rich world. Sci. Amer., 266, 68-74. Bonan, G., 1996a: A Land Surface Model (LSM version 1.0) for 
ecological, hydrological, and atmospheric studies: Technical description and user's guide. NCAR Tech. Note NCAR/TN$417+$ STR, National Center for Atmospheric Research, Boulder, CO, 150 pp. [Available from NCAR, P.O. Box 3000, Boulder, CO 80307.]

— 1996b: The NCAR Land Surface Model (LSM version 1.0) coupled to the NCAR Community Climate Model. NCAR Tech. Note NCAR/TN-429+STR, National Center for Atmospheric Research, Boulder, CO, 171 pp. [Available from NCAR, P.O. Box 3000, Boulder, CO 80307.]

Collatz, G., J. Ball, C. Grivet, and J. A. Berry, 1991: Physiological and environmental regulation of stomatal conductance, photosynthesis, and transpiration: A model that includes a laminar boundary layer. Agric. For. Meteor., 54, 107-136.

Dickinson, R., 1984: Modeling evapotranspiration for three-dimensional global climate models. Climate Processes and Climate Sensitivity, Geophys. Monogr., No. 29, Amer. Geophys. Union, 58-72.

—, A. Henderson-Sellers, P. Kennedy, and M. S. Wilson, 1986: Biosphere-Atmosphere Transfer Scheme (BATS) for the NCAR Community Climate Model. NCAR Tech. Note NCAR/TN275+STR, National Center for Atmospheric Research, Boulder, CO, 69 pp. [Available from NCAR, P.O. Box 3000, Boulder, CO 80307.]

— — - and 1993: Biosphere-Atmosphere Transfer Scheme (BATS) version 1e as coupled to the NCAR Community Climate Model. NCAR Tech. Note NCAR/TN-387+STR, National Center for Atmospheric Research, Boulder, CO, 72 pp. [Available from NCAR, P.O. Box 3000, Boulder, CO 80307.]

Eamus, D., and P. Jarvis, 1989: Effects of increase in global atmospheric $\mathrm{CO}_{2}$ concentration. Adv. Ecol. Res., 19, 1-55.

Henderson-Sellers, A., T. Durbidge, A. Pitman, R. Dickinson, P. Kennedy, and K. McGuffie, 1993: Tropical deforestation modelling local to regional-scale climate change. J. Geophys. Res., 98, $7289-7315$.

— K. McGuffie, and C. Gross, 1995: Sensitivity of global climate model simulations to increased stomatal resistance and $\mathrm{CO}_{2}$ increases. J. Climate, 8, 1738-1756.

Hileman, D. R., N. N. C. Bhattacharya, P. Ghosh, P. Biswas, K. Lewin, and G. R. Hendrey, 1992: Responses of photosynthesis and stomatal conductance to elevated carbon dioxide in field-grown cotton. Crit. Rev. Plant Sci., 11, 227-231.

Idso, S., and A. Brazel, 1984: Rising atmospheric carbon dioxide concentrations may increase streamflow. Nature, 312, 51-53.

Jarvis, P., 1976: The interpretation of leaf water potential and stomatal conductance found in canopies in the field. Philos. Trans. Roy. Soc. London, 273B, 593-610.

Kiehl, J., J. Hack, G. Bonan, B. Boville, B. Briegleb, D. Williamson, and P. Rasch, 1996: Description of the NCAR Community Climate Model (CCM3) Tech. Rep. NCAR/TN-420+STR, National Center for Atmospheric Research, Boulder, CO, 152 pp. [Available from NCAR, P.O. Box 3000, Boulder, CO 80307.]

Langbein, W. B., 1949: Annual runoff in the United States. Circular 5, U.S. Geological Survey, U.S. Dept. of the Interior, Washington, DC.

Legates, D. R., and C. J. Willmott, 1990: Mean seasonal and spatial variability in gauge-corrected, global precipitation. Int. J. Climatol., 10, 111-127.

Morison, J., and R. Gifford, 1984: Plant growth and water use with limited water supply in high $\mathrm{CO}_{2}$ concentrations. Aust. J. Plant Physiol., 11, 361-374.

Morrill, J. C., 1995: A comparison of CCM2/BATS simulated precipitation and runoff with observed values over the continental United States. M.S. thesis, Department of Hydrology and Water Resources, The University of Arizona, 150 pp. [Available from jean@hwr.arizona.edu.]

Nash, L., 1991: The implications of climatic change for streamflow and water supply in the Colorado Basin. Managing Water Resources in the Southwest under Conditions of Climate Uncertainty, A Proceedings, S. J. Burges, Ed., National Academic Press, $158-176$.

Niyogi, D., and S. Raman, 1997: Comparison of four different stomatal resistance schemes using FIFE observations. J. Appl. Meteor., 36, 903-917.

Pollard, D., and S. Thompson, 1995: Use of a land-surface-transfer scheme (LSX) in a global climate model: The response to doubling stomatal resistance. Global Planet. Change, 10, 129-161.

Radoglou, K., P. Aphalo, and P. Jarvis, 1992: Response of photosynthesis, stomatal conductance and water use efficiency to elevated $\mathrm{CO}_{2}$ and nutrient supply in acclimated seedlings of phaseolus vulgaris L. Ann. Bot., 70, 257-264.

Revelle, R. R., and P. E. Waggoner, 1983: Effects of a carbon dioxideinduced climatic change on water supplies in the western United States. Changing Climate, National Academy Press, 419-432.

Sellers, P., J. A. Berry, G. J. Collatz, C. B. Field, and F. G. Hall, 1992: Canopy reflectance, photosynthesis and transpiration. III. A reanalysis using improved leaf models and a new canopy integration scheme. Remote Sens. Environ., 42, 187-216.

- , and Coauthors, 1996: Comparison of radiative and physiological effects of doubled atmospheric $\mathrm{CO}_{2}$ on climate. Science, 271, 1402-1406.

Shaikh, M., 1996: Precipitation simulation in general circulation models: Impact of horizontal resolution and improved land surface scheme. Ph.D. thesis, The University of Arizona, $246 \mathrm{pp}$.

Skiles, J., and J. D. Hanson, 1994: Responses of arid and semiarid watersheds to increasing carbon dioxide and climate change as shown by simulation studies. Climatic Change, 26, 377-397.

Stockton, C., and W. R. Boggess, 1979: Geohydrological implications of climate change on water resource development. Tech. Rep., U.S. Army Coastal Engineering Research Center, Fort Belvoir, VA.

Wallis, J., D. P. Lettenmaier, and E. F. Wood, 1990: A daily hydroclimatological data set for the continental U.S. Water Resour. Res., 27, 1657-1664.

Wigley, T., and B. Santer, 1990: Statistical comparison of spatial fields in model validation, perturbation, and predictability experiments. J. Geophys. Res., 95, 851-865.

Yang, Z.-L., R. Dickinson, A. Henderson-Sellers, and A. J. Pitman, 1995: Preliminary study of spin-up processes in land surface models with the first stage data of Project for Intercomparison of Land Surface Parameterization Schemes Phase 1(a). J. Geophys. Res., 100, 16 533-16 578. 